\title{
Targeted mutations of breast cancer susceptibility gene homologs in mice: lethal phenotypes of Brca1, Brca2, Brca1/Brca2, Brca1/p53, and Brca2/p53 nullizygous embryos
}

\author{
Thomas Ludwig, ${ }^{1}$ Deborah L. Chapman, ${ }^{2}$ Virginia E. Papaioannou, ${ }^{2}$ and Argiris Efstratiadis ${ }^{2,3}$ \\ Departments of ${ }^{1}$ Anatomy and Cell Biology and ${ }^{2}$ Genetics and Development, Columbia University, New York, New York \\ 10032 USA
}

\begin{abstract}
Mutations of the human BRCA1 and BRCA2 genes encoding tumor suppressors have been implicated in inherited predisposition to breast and other cancers. Disruption of the homologous mouse genes Brca1 and Brca2 by targeting showed that they both have indispensable roles during embryogenesis, because nullizygous embryos become developmentally retarded and disorganized, and die early in development. In Brca1 mutants, the onset of abnormalities is earlier by one day and their phenotypic features and time of death are highly variable, whereas the phenotype of Brca2 null embryos is more uniform, and they all survive for at least 8.5 embryonic days. Observations with Brca1/Brca2 double nullizygotes raise the possibility that the two developmental pathways could be linked. Interestingly, the impact of the Brca1 or Brca2 null mutation is less severe in a $p 53$ null background.
\end{abstract}

[Key Words: Brca1; Brca2; p53; mouse mutant; embryonic lethality]

Received February 11, 1997; revised version accepted April 11, 1997.

Two genes of unknown biochemical function, $B R C A 1$ (Miki et al. 1994) and BRCA2 (Wooster et al. 1995; Tavtigian et al. 1996), have been implicated in inherited predisposition to female breast cancer that is a causal factor for the disease in $\sim 5 \%-10 \%$ of all patients (for review, see Claus et al. 1991; Easton et al. 1993; Szabo and King 1995; Cannon-Albright and Skolnick 1996; Marcus et al. 1996; Stratton and Wooster 1996). Mutations of BRCA1 also predispose to ovarian cancer (see, e.g., Easton et al. 1995; Gayther et al. 1995; Johannsson et al. 1996; Serova et al. 1996), whereas mutations of $B R C A 2$ are involved in male breast cancer and apparently in pancreatic cancer (Schutte et al. 1995; Goggins et al. 1996; Teng et al. 1996). Loss of heterozygosity (LOH) consistently affecting the wild-type allele in tumors from patients carrying $B R C A 1$ or BRCA2 mutations (Smith et al. 1992; Neuhausen and Marshall 1994; Collins et al. 1995) indicated that these genes encode tumor suppressors. Moreover, $B R C A 1$ antisense strategies using cultured cells resulted either in acceleration of proliferation (Thompson et al. 1995) or cell transformation (Rao et al. 1996). Most of the mutations affecting the BRCA1 gene (Szabo and King

${ }^{3}$ Corresponding author.

E-MAIL arg@cucefa.ecc.columbia.edu; FAX (212) 923-2090.
1995; Cannon-Albright and Skolnick 1996; Feunteun and Lenoir 1996; Stratton and Wooster 1996; Xu and Solomon 1996) or the BRCA2 gene (Wooster et al. 1995; Couch et al. 1996; Neuhausen et al. 1996; Phelan et al. 1996; Tavtigian et al. 1996; Teng et al. 1996; Thorlacius et al. 1996) result in truncated protein products. In sporadic tumors, somatic $B R C A 1$ or $B R C A 2$ mutations occur infrequently (Lancaster et al. 1996; Miki et al. 1996; Stratton and Wooster 1996; Teng et al. 1996).

The major BRCA1 mRNA (Miki et al. 1994; Xu et al. 1995; Brown et al. 1996; Smith et al. 1996) encodes a nuclear phosphoprotein (X. Chen et al. 1996; C.F. Chen et al. 1996) of 1863 amino acid residues, but differential splicing events generate additional mRNAs that are only partially characterized (C.F. Chen et al. 1996; Thakur et al. 1997; Wilson et al. 1997). The amino-terminal portion of the BRCAl protein contains a RING finger domain (Freemont 1993; Saurin et al. 1996) that should be important for function, because it is invariant between the human and mouse genes, otherwise exhibiting only $58 \%$ sequence identity at the amino acid level (Abel et al. 1995; Bennett et al. 1995; Lane et al. 1995; Sharan et al. 1995). The carboxy-terminal region of BRCA1, which acts as a transcriptional transactivator when fused with the GAL4 DNA-binding domain (Chapman and Verma 1996; Monteiro et al. 1996), contains two copies of a 
domain (BRCT; Koonin et al. 1996) exhibiting weak similarity with the mammalian p53-binding protein $53 \mathrm{BP} 1$; with the yeast RAD9 protein that is involved in cell cycle arrest at checkpoints on DNA damage; and with other proteins (Koonin et al. 1996; Bork et al. 1997; Callebaut and Mornon 1997), including BARD1 (Wu et al. 1996) that interacts with BRCA1 in vivo. The highly charged protein of 3418 residues encoded by $B R C A 2$ is novel and, like BRCA1, not well conserved between humans and mice $159 \%$ sequence identity at the amino acid level; Connor et al. 1997; Sharan and Bradley 1997). Eight variable internal repeats of unknown significance have been identified in the region ecoded by BRCA2 exon 11 (Bork et al. 1996), which are also present in the homologous proteins of six other mammals, including mouse (Bingell et al. 1997).

To provide clues about the normal function of Brca1 and Brca2, we have disrupted these genes in mice by targeted mutagenesis. Our results demonstrate that either of these mutations results in early embryonic lethality in homozygous mutants, while heterozygous and double heterozygous mice are indistinguishable from wild type. We have also assessed the combined effects of the two mutations in double nullizygous embryos, and have examined potential relationships between the Brca1 or Brca2 and p53 functions. While this work was in progress, three reports appeared (Gowen et al. 1996; Hakem et al. 1996; Liu et al. 1996) describing Brca1 targeted mutations. Similarities and differences between these studies and our results are discussed.

\section{Results}

Targeted disruption of the mouse Brcal and Brca2 genes

To generate a null mutation of the Brca1 gene, we used a replacement vector that would delete a DNA fragment consisting of exon 2, encoding a part of the conserved RING finger motif, and portions of its flanking introns (see Materials and Methods). The targeted allele was designated Brca1 ${ }^{\text {ex2}}$. Similarly, we disrupted the Brca2 gene by replacing a segment of exon 11 with a neo cassette. Because of a frame-shift in the targeted allele $\left(B r c a 2^{e x 11}\right)$, a stop codon is encountered in the neo sequence. Therefore, any processed Brca2 transcript would generate a truncated protein product that should be inactive.

Genotyping of progeny (129/Sv $\times$ C57BL/6J) heterozygous for either the Brca1 or the Brca2 mutation showed that these mice were indistinguishable from their wildtype littermates. Brca 1 heterozygous females are still tumor-free at the age of 15 months, whereas of the Brca2 heterozygotes, the oldest of which are eight months old, only a single four-month-old female developed a squamous cell carcinoma of the skin in the thoracic region (data not shown). However, the appearance of this carcinoma cannot be formally attributed to loss of Brca2 tumor suppressing activity, as PCR analysis of DNA ex- tracted from histological sections and corresponding exclusively to tumor tissue indicated that Brca2 heterozygosity was maintained, and sequence analysis was not performed to determine whether the nontargeted allele was mutated.

\section{Embryonic lethality of nullizygous Brcal and Brca2 mutants: comparative analysis}

Genotyping of 183 progeny derived from intercrosses of heterozygous Brca1 $1+1-\mid$ mice showed that 59 were wild type, whereas the remaining 124 were heterozygous for the mutation. In analogous crosses between $\operatorname{Brca} 2(+\mid-1$ heterozygotes, 160 pups were analyzed, 58 of which were wild type and 102 were heterozygous. In both cases, the complete absence of nullizygous mutants among these offspring, whereas heterozygous and wild-type progeny were obtained at the expected ratio, indicated that in the homozygous state the Brca1 and Brca2 null mutations result in embryonic lethality.

To analyze the lethal phenotypes, pregnant females from matings between heterozygous Brca1 or Brca2 mutants were sacrificed at different times post coitum, and embryos were examined in histological sections of dissected decidua and then genotyped. The gross morphology of additional embryos, some of which were genotyped, was also examined. The data are summarized in Table 1. In both the histological and the gross morphological analyses, we observed a high incidence of empty decidua in the Brca1 series. Although genotyping was precluded, it is likely that most, if not all, of these empty decidua corresponded to Brca1 null mutants, because their occurrence in the Brca2 series was very rare (Table 1). Moreover, a number of decidua contained only giant cells and extraembryonic membranes, which on genotyping were found to be Brcal mutants (eight cases; five shown in Table 1). Therefore, the decidua with or without embryonic remnants are considered as one of the aspects of the variable Brca1 null phenotype. In contrast, the phenotypic features of the Brca2 nullizygotes are overall quite uniform, especially before embryonic day 9.5 (E9.5).

At the earliest age examined (E5.5), the wild-type and heterozygous embryos (hereafter referred to indiscriminately as "normal," for brevity) were small egg cylinders with distinct embryonic and extraembryonic regions, which had initiated the formation of a proamniotic cavity. Moreover, the visceral endoderm was differentiated into extraembryonic (columnar) and embryonic (squamous) layers (Fig. 1A). This characteristic regional difference in the appearance of endodermal cells was not evident in Brca1 nullizygous mutants, which were recognizable morphologically as small and shorter-thannormal egg cylinders without a visible demarcation of embryonic and extraembryonic regions (Fig. 1B). A proamniotic cavity was present in only one of five examined mutant embryos (data not shown). The primary giant cells, Reichert's membrane and distal endoderm of the mutants did not differ from those of the controls. 
Table 1. Embryonic phenotypes

\begin{tabular}{|c|c|c|c|c|c|c|c|c|c|c|c|}
\hline & \multirow[b]{2}{*}{ Genotype $\rightarrow$} & \multicolumn{4}{|c|}{ Normal } & \multicolumn{3}{|c|}{ Abnormal } & \multicolumn{2}{|c|}{$\begin{array}{l}\text { Giant cells } \pm \\
\text { membranes only }\end{array}$} & \multirow{2}{*}{$\begin{array}{c}\text { Empty } \\
\text { decidua } \\
\text { (N.D.) }\end{array}$} \\
\hline & & $+1+$ & $+1-$ & $-1-$ & N.D. & $+1-$ & $-1-$ & N.D. & $-1-$ & N.D. & \\
\hline \multicolumn{12}{|c|}{ A. Brcal } \\
\hline \multicolumn{12}{|c|}{ Histology } \\
\hline E5.5 & & 3 & 5 & & & & 5 & & & 1 & 1 \\
\hline E6.5 & & 2 & 5 & & & & 2 & & & & \\
\hline E7.5 & & 6 & 9 & & 7 & & 4 & 2 & 1 & 1 & 1 \\
\hline E8.5 & & 2 & 5 & & & & 4 & & 1 & 1 & 1 \\
\hline \multicolumn{12}{|c|}{ Gross morphology } \\
\hline E6.5 & & & & & 46 & & & 8 & & & 6 \\
\hline E7.5 & & 4 & 15 & & 60 & 1 & 3 & 15 & & 1 & 5 \\
\hline E8.5 & & & & & 6 & & & 2 & 3 & & 2 \\
\hline E9.5 & & 6 & 10 & & 23 & & 6 & 3 & & 2 & 6 \\
\hline \multicolumn{12}{|c|}{ B. Brca2 } \\
\hline \multicolumn{12}{|c|}{ Histology } \\
\hline E5.5 & & & & & 15 & & & & & & \\
\hline E6.5 & & 4 & 9 & 2 & & & 2 & & & & \\
\hline E7.5 & & 6 & 11 & & 4 & & 8 & 2 & & & \\
\hline E8.5 & & 7 & 11 & & 2 & & 5 & 2 & & & 1 \\
\hline \multicolumn{12}{|c|}{ Gross morphology } \\
\hline E7.5 & & & & & 22 & & & 6 & & & \\
\hline E8.5 & & & & & 17 & & & 14 & & & 1 \\
\hline E9.5 & & 3 & 11 & & & & 5 & & & & \\
\hline
\end{tabular}

The genotyping data do not correspond to a random sample of embryos. However, if only a subset of the data from complete litters are considered, the expected Mendelian ratios are observed (not shown).

(N.D.) Genotype not determined.

At E6.5, the Brca1 mutant embryos were two-layered cylinders that were about half of the normal size (Fig. 1, cf. C and Dl. Although the boundary between embryonic and extraembryonic regions was poorly demarcated, differentiation of the primary endoderm into columnar and squamous epithelium had occurred. The embryonic portion was disproportionately smaller (Fig. 1D) and, in contrast to the normal embryos, the mutants lacked amniotic folds. The primary giant cells associated with the mutant embryos were prominent and very large (at the upper size limit of the normal range). Of four Brca2 mutant embryos examined at this age, two were indistinguishable from their normal littermates, whereas the other two were slightly shorter-than-normal egg cylinders with expanded proamniotic cavities (see Fig. 1E). This reduction in size was disproportionate for the extraembryonic and embryonic regions, the latter being affected more severely, as in the case of the Brca1 nullizygotes.

The normal embryos that were examined at E7.5 had gastrulated and possessed a third (mesodermal) germ layer and, with one exception (1/22 in the Brcal series), fused amniotic folds (Fig. 1F). Some of the normal embryos in the Brca1 series and all of the normal embryos in the Brca2 series exhibited head-folds. The Brca1 nullizygotes were small egg cylinders that lacked amniotic folds, whereas presence of mesoderm was not readily visible. However, large primary giant cells, a small ectoplacental cone, Reichert's membrane with distal endoderm, extraembryonic ectoderm and columnar endoderm, and a meager epiblast and squamous endoderm surrounding a proamniotic cavity containing some pyknotic nuclei and cell debris were discernible (Fig. 1G). The phenotype of one of the mutants was more severe. It consisted of a loose network of giant cells, and a cluster of cells surrounded by a small sac with the appearance of distal endoderm (data not shown). In contrast to the Brcal mutants, the Brca2 nullizygotes were clearly three-layered egg cylinders with mesoderm present in the amniotic folds and in the disproportionately reduced embryonic region (Fig. $1 \mathrm{H}$ ). However, the amniotic folds were not fused and the proamniotic cavity, containing cellular debris and some pyknotic nuclei, communicated with the ectoplacental cavity. The embryos were surrounded by large giant cells and had a prominent ectoplacental cone and extraembryonic ectoderm. Despite the presence of pyknotic nuclei in the proamniotic cavities of some Brca1 or Brca2 embryos that occasionally exceeded the level seen in controls, signs of excessive cell death in embryonic regions were not observed in any of the mutants at this or any other age.

At E8.5, the normal embryos in the Brca1 series had head-folds and up to eight somites, whereas five genotyped Brcal mutants were variable in shape and developmental stage (Fig. 1I-K). One of them consisted only of giant cells, whereas in the embryonic region of three other mutants, the columnar cells of the stubby epiblast were surrounded by squamous endoderm, but there was 
e5.5

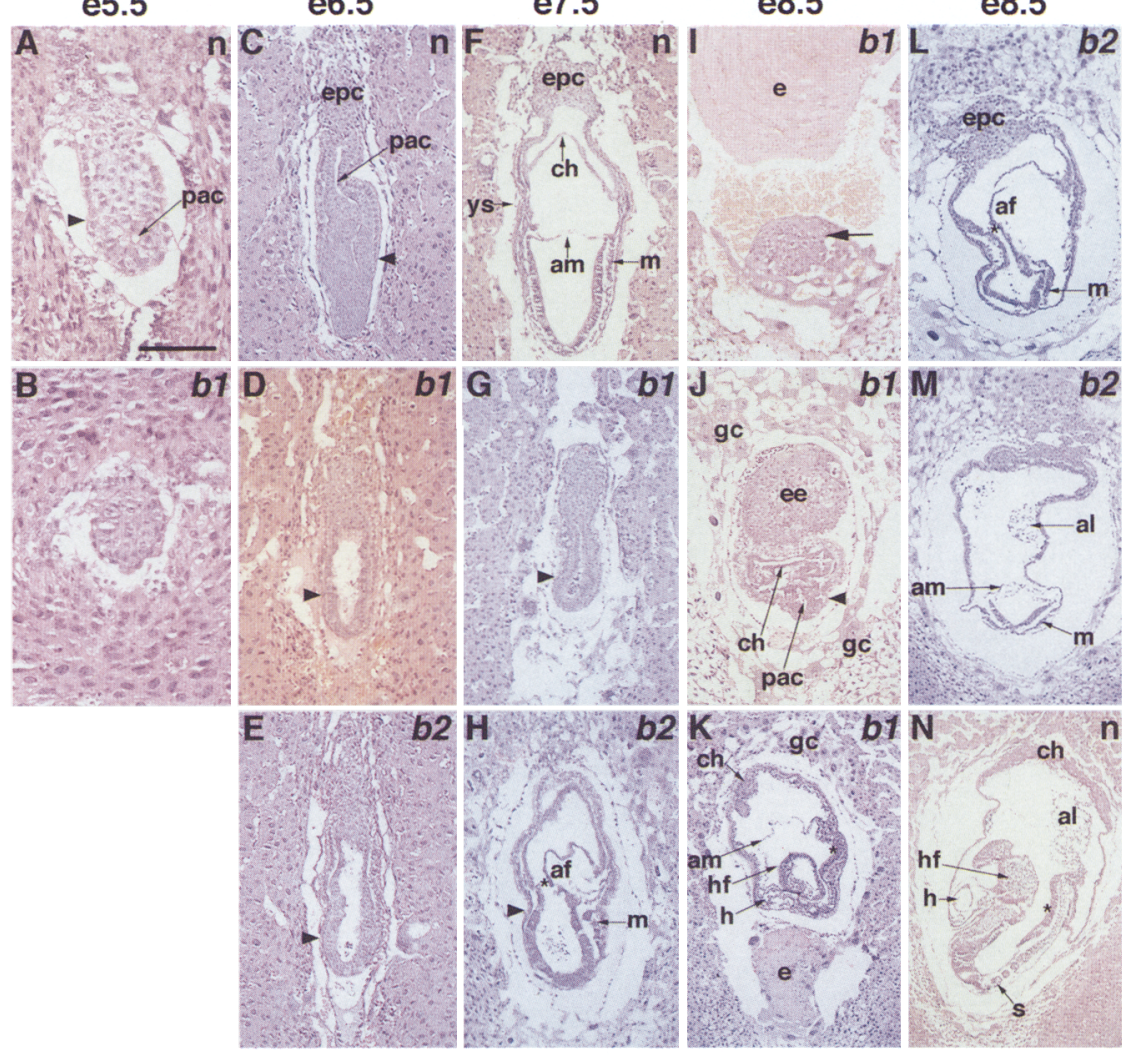

Figure 1. Histological comparisons of normal and Brca1 and Brca2 nullizygous embryos. Sections of normal embryos $(\mathrm{n})$ and Brca1 (b1) and Brca2 (b2) mutants are displayed in five columns corresponding to the embryonic ages indicated on top. (A) Normal (Brca1 heterozygous) elongating egg cylinder with the beginning of a proamniotic cavity (pac). In this and subsequent panels, an arrowhead marks the boundary between the extraembryonic and embryonic regions. At this boundary, the endoderm changes from columnar to squamous epithelium. (B) Brca1 nullizygous embryo. Endoderm surrounding the primitive ectoderm is evident, but the egg cylinder has not elongated and there is not yet any distinction between the extraembryonic and embryonic regions. $\{C \mid$ Wild-type egg cylinder with proamniotic cavity (pac); ectoplacental cone $(\mathrm{epc}) .(D, E)$ Brca1 and Brca2 nullizygous egg cylinders with prominent proamniotic cavities. $(F)$ Brcal heterozygous embryo with three distinct germ layers: (m) mesoderm; (am) amnion; (ch) chorion; and (ys) yolk sac. $(G)$ Brca1 nullizygous embryo. There are no amniotic folds and the proamniotic cavity, which contains cellular debris, does not extend to the proximal region of the extraembryonic ectoderm. (H) Brca2 nullizygous embryo. The amniotic folds (af) have formed, but not fused $\left({ }^{*}\right)$. Mesoderm $(\mathrm{m})$ is evident in both the embryonic and extraembryonic regions. Cellular debris is present in the proamniotic cavity. (I) An arrow indicates the remains of a severely affected Brca1 nullizygous embryo consisting of giant cells and a mass of undifferentiated tissue. A large eosinophilic mass (e) is present mesometrially. (J) A less severly affected Brca1 nullizygous embryo. A loose network of giant cells $(\mathrm{gc})$ surrounds Reichert's membrane and distal endoderm. The extraembryonic ectoderm (ee) has the appearance of a solid cellular mass, although a chorion (ch) has formed and extraembryonic mesoderm is present. In the embryonic region, the epiblast and endoderm surround a small amniotic cavity. $(K)$ Sagittal section of the most advanced Brca1 nullizygote observed in this study. The heart (h), head-fold (hf), posterior neural plate $\left({ }^{\star}\right)$ and extraembryonic membranes are shown. An eosinophilic mass $(e)$ is present antimesometrially. $\{L\}$ Brca2 nullizygous embryo showing development of an ectoplacental cone (epc) and amniotic folds (af), but with a persistent proamniotic canal $\left({ }^{*}\right)$. The embryonic region is underdeveloped, but contains mesoderm $(\mathrm{m})$. (M) Transverse section of a Brca2 nullizygous embryo with an allantois (al), a diffuse amnion (am), and three germ layers in the underdeveloped embryonic region. (N) Sagittal section of a wild-type embryo with head-folds (hf), heart $(\mathrm{h})$, somites $(\mathrm{s})$, neural plate $\left({ }^{\star}\right)$, and the allantois (al) attached to the chorion (ch). Scale bar, $100 \mu \mathrm{m}(A, B) ; 180 \mu \mathrm{m}(C-E) ; 250 \mu \mathrm{m}(F-I, L)$; $400 \mu \mathrm{m}(K, M)$; and $500 \mu \mathrm{m}(N)$.

no visible mesoderm. However, extraembryonic mesoderm was detectable, whereas the extraembryonic ectoderm, instead of being hollow, had the appearance of a solid cellular mass (Fig. 1J). In two of these mutants a distinct chorion was formed, therefore creating a small ectoplacental cavity. The ectoplacental cone was very small with little or no placental development. The embryos were surrounded by a loose network of giant cells with large nuclei (Fig. 1J,K). The fifth Brca1 mutant was more advanced than any other examined; it contained an expanded yolk sac with blood islands, an amnion and an allantois, whereas the embryonic region, although severely reduced in size, was quite organized and had headfolds, a neural tube closed in one region, and a heart (Fig. 1K). The normal embryos in the Brca2 series had turned and contained somites (Fig. 1N), whereas the Brca2 nullizygotes were much smaller and lacked somites (Fig.
$1 \mathrm{~L}, \mathrm{M})$. Despite their reduced size, all of these mutants possessed embryonic mesoderm and had an anterior/ posterior axis. Several of them were forming head-folds and exhibited rudimentary heart differentiation. All mutant embryos had a yolk sac with blood islands, a prominent allantois, and a well-developed chorion. The development of the amnion, however, was poor, with a loose mesodermal layer (Fig. 1M), and, in one of the mutants (1/7), the proamniotic canal persisted (Fig. 1L). The embryos were surrounded by giant cells and had developing placentas with ectoplacental cones.

Gross morphological analysis was consistent with the previous observations and indicated that at E9.5 the range of phenotypes of Brca1 mutants was similar to that observed at E8.5, except that the most advanced embryos had developed an axial embryonic region and possessed an allantois and an expanded yolk sac with blood islands 
(Table 1). In contrast to this phenotypic range of Brca1 mutants, the E9.5 Brca2 nullizygotes were all similar, and exhibited a reduced embryonic region with headfolds, a large allantois, and an expanded yolk sac with visible blood. One of these mutants had three to four somites, whereas another had a beating heart.

Of 60 genotyped Brca1 mutant embryos, nine (15\%) were associated with eosinophilic masses present in the implantation crypt either on the mesometrial or on the antimesometrial side, which were infiltrated with maternal neutrophils and possibly with endothelial cells (see Fig. 1I,K). This material had the appearance of a fibrin-like deposit probably formed after hemorrhage of uterine vessels. Twenty additional eosinophilic masses were associated with nongenotyped abnormal embryos or with empty decidua. In the Brca2 series, on the other hand, the appearance of these deposits was very infrequent, and observed in association with a single empty deciduum and only $1 / 32(3 \%)$ genotyped Brca2 mutant embryos.

\section{Cell proliferation assay in Brca2 mutants}

Previously, the growth deficiency of Brca1 nullizygotes was correlated with decreased cell proliferation (Hakem et al. 1996; Liu et al. 1996). To ascertain whether the same occurs in Brca2 mutants, pregnant females from heterozygous crosses were injected with 5-bromo-2'-deoxyuridine (BrdU) $1 \mathrm{hr}$ before sacrifice, and decidua recovered at E6.5 and E7.5 were processed for histology. Incorporation of BrdU into DNA was assayed by counting labeled and unlabeled nuclei in the ectoplacental cone, the extraembryonic region and the embryonic region in representative sagittal sections close to the midline, whereas other sections were used for genotyping. Statistical differences in the averaged percentages of BrdU-positive nuclei were not detected between the three embryonic regions examined either in mutants or in controls (Student's $t$-test; $P<0.05$ ). Therefore, for comparison, overall averages for the embryos of each group were used. At E6.5, there was no difference between the mean values of the two groups; $67.5 \pm 2.7 \%$ and $68.4 \pm 1.8 \%$ of the nuclei were labeled in controls and mutants, respectively (three genotyped embryos in each groupl. The percentage of BrdU-positive cells was within the normal range even in one of the embryos of the latter group that was morphologically distinguishable as a mutant. At E7.5, however, the corresponding values were significantly different: $67.6 \pm 2.3 \%$ and $52.3 \pm 2.0 \%$ for controls and mutants, respectively (two embryos in each group). We conclude that, at the time when the Brca2 phenotype becomes unequivocally detectable by morphology, growth retardation is correlated with relative hypoproliferation.

\section{Expression of marker genes}

Previous reports suggested that the Brca1 mutants fail to form mesoderm (Hakem et al. 1996; Liu et al. 1996). In our morphological analyses, however, extraembryonic mesoderm was detectable, whereas mesoderm in the embryonic region was present in the most advanced mutants (see Fig. 1K). To investigate further the differentiation of primitive streak and mesoderm, we used wholemount in situ hybridization to examine E7.5 Brca1 mutants and control littermates for the expression of the gene Brachyury $(T)$, an early marker of mesodermal cells (Fig. 2A). At this stage, $T$ is expressed in the primitive streak and the head process (see Wilkinson et al. 1990; Herrmann 1991!, and all 10 wild-type embryos that were examined exhibited this pattern of labeling. In contrast, only $3 / 5$ mutants examined were labeled with the $T$ probe in a region corresponding to the primitive streak, exhibiting variable extent and intensity of signal that was commensurate with the degree of their development (see Fig. 2A). Parallel examination of E8.5 Brca2 mutants, in which mesoderm is morphologically detectable, verified the expected expression of $T$ in the primitive streak and the node (Fig. 2A).

We also examined E7.5 Brca2 mutants and E8.5 Brca1 and Brca2 mutants for expression of Oct-4 transcripts encoding a POU transcription factor (Fig. 2B). In postimplantation embryos, Oct-4 is specifically expressed in
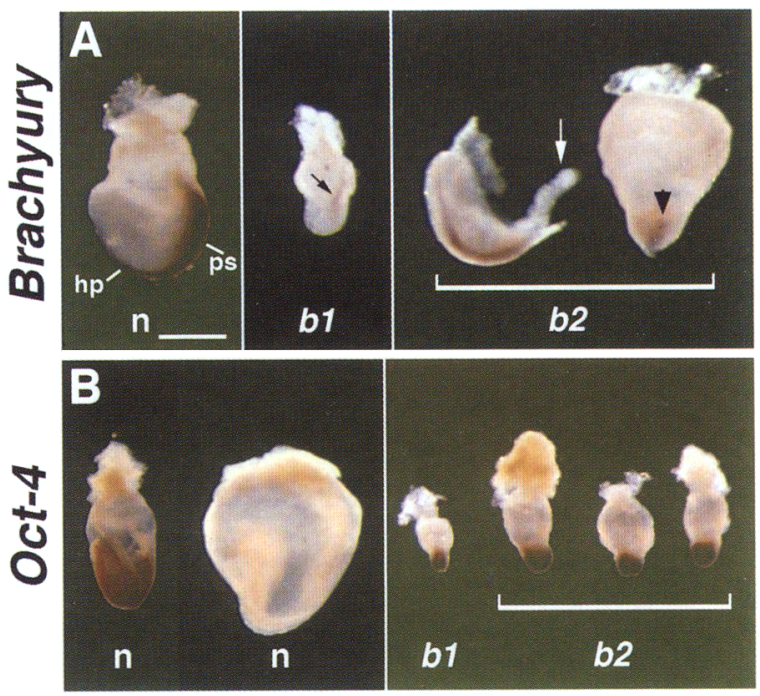

Figure 2. Expression of Brachyury $(T)$ and Oct-4 genes examined by whole-mount in situ hybridization. $\{A \mid$ Shown from left to right are: A normal (n) E7.5 embryo expressing $T$ (brown stripe) in the primitive streak (ps) and the head process (hp); an E7.5 Brca1 (b1) null mutant showing a posterior stripe of $T$ expression (arrow); an E8.5 Brca2 (b2) mutant embryo (side view) with yolk sac removed (expression of $T$ is detectable in an axial stripe along the length of the embryo; the arrow indicates the allantois); and an E8.5 Brca2 mutant embryo (posterior view) with a stripe of $T$ expression (arrowhead). (B) Shown from left to right are: An E7.5 normal embryo with evident expression of Oct-4; an E8.5 normal embryo, in which the Oct-4 expression has become undetectable; an E8.5 Brca1 mutant embryo; and an E7.5 and two E8.5 Brca2 mutant embryos. The level of Oct-4 expression remains high in the epiblast of all mutant embryos. Scale bar, $350 \mu \mathrm{m}\langle A|$ and $600 \mu \mathrm{m}(B)$. 
the epiblast at high levels, but, as development progresses, the level of expression declines, and after E8.5 becomes restricted to the primordial germ cells (Schöler et al. 1990; Yeom et al. 1996). All of the normal specimens examined showed this characteristic pattern of labeling, including confinement of signal to germ cells in the most advanced embryos. In the developmentally retarded mutant embryos of both types, however, Oct-4 signal remained positive in the embryonic portion of the egg cylinders (Fig. 2B).

\section{In vitro outgrowth of blastocysts}

Our histopathological analyses indicated that the Brca1 and Brca2 null mutations are first manifestated with developmental delays at E5.5 and E6.5, respectively, and subsequently result in dysmorphogenesis and embryonic death. To complement these data, we examined E3.5 blastocysts that were cultured in vitro for four or five days and subsequently genotyped. As shown in Table 2, the absence of Brcal is associated with a failure of the inner cell mass (ICM) to grow and survive in outgrowths, although an exception was noted in one of 10 developing mutant blastocysts. Abnormal ICM development became evident in some Brca1 mutants after only two days in culture, when the ICM appeared smaller than normal. Subsequently, these small ICMs diminished further in size and many disappeared by four or five days in culture, leaving behind a monolayer of trophoblast cells with large nuclei (Fig. 3, cf. B with A). In contrast, only a small proportion of wild-type and heterozygous blastocysts exhibited small ICMs, and only one of these outgrowths lost its ICM entirely after four days of culture.

The absence of Brca2 was also associated with abnormal ICM development evident in some mutants as early as two days in culture, but some of the nullizygous outgrowths appeared normal until day four or five. The most striking feature of the mutant phenotype was a loss of cohesiveness in the ICM, resulting in an irregular appearance and a reduction in size (Fig. 3D). In a few cases, the ICMs of mutants had disappeared by five days in culture. In contrast, the ICMs of wild-type and heterozygous outgrowths were generally large and cohesive

Table 2. In vitro outgrowth of blastocysts after 4 days in culture

\begin{tabular}{lcrcr}
\hline & \multicolumn{4}{c}{ Genotype } \\
\cline { 2 - 3 } & \multicolumn{2}{c}{ Brca1 } & & Brca2 \\
\cline { 2 - 3 } \cline { 5 - 6 } & $+/+$ or $+/-$ & $-1-$ & $+1+$ or $+/-$ & $-1-$ \\
\hline Total number examined & 31 & 10 & 36 & 10 \\
Normal & 28 & 1 & 33 & 2 \\
Small ICM & 2 & 4 & 1 & 3 \\
Disorganized ICM & & & 2 & 5 \\
No ICM & 1 & 5 & &
\end{tabular}

Combined data from two experiments in each case.
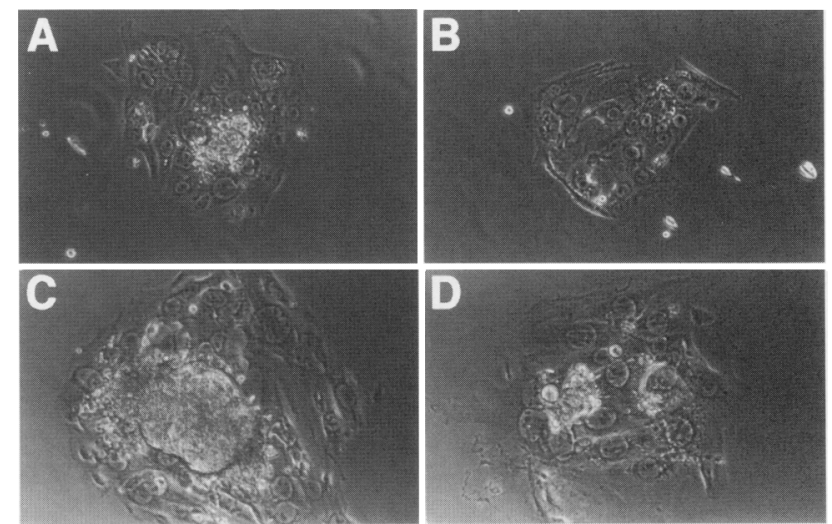

Figure 3. In vitro blastocyst outgrowths after five days in culture. (A) Wild-type outgrowth from the Brca1 series with an ICM and a monolayer of trophoblast giant cells. (B) Brca1 nullizygous outgrowth lacking an ICM. (C) Wild-type outgrowth from the Brca2 series with a well-developed ICM and trophoblast giant cells. $(D)$ Brca2 nullizygous outgrowth showing a small and disorganized ICM. The difference in appearance between controls $(A, C)$ reflects variation between experiments.

(Fig. 3C), with only two of them acquiring a disorganized appearance similar to that of the Brca2 mutants.

It is apparent from these results that the abnormal development of outgrowths was more severe in Brca1 than in Brca2 nullizygotes. Although the earliest time of onset did not differ between the two cases, the average time of onset was earlier by one day for Brca1. Moreover, the ICM cells died and disappeared in the majority of the Brca1 mutants by four to five days, whereas some ICM cells survived in most of the Brca2 mutants. In both cases, however, there was an apparent paucity of small trophoblast cells, although large giant cells were present.

\section{Phenotype of Brca1/Brca2 double nullizygotes}

To examine the combined effect of the Brca1 and Brca2 null mutations, we intercrossed Brca1(+/-)/Brca2(+/-) double heterozygotes and recovered 51 decidual swellings at E9.5, which were dissected, examined morphologically, and then genotyped by Southern analysis (Table 3). Nine of the decidua were empty, whereas among the remaining 42 , all nine expected genotypes were recovered at expected frequencies $\left(\chi^{2}=13.2,8 d f\right.$, $P>0.05$ ). Embryos with at least one wild-type allele of each gene were normal and had 25-30 somites, whereas embryos lacking only Brcal or only Brca2 exhibited phenotypic features characteristic for each mutation (see Fig. 4A-C and Table 3). Two of the recovered decidua contained double nullizygous mutants. One of these was an embryo with an allantois and a severely reduced embryonic region without head-folds (Fig. 4C), whereas the other consisted of a yolk sac and giant cells only. Therefore, in comparison with the two classes of single nullizygotes in terms of the degree of development, embryos 
Table 3. Phenotypes of E9.5 embryos from intercrosses between Brcal (+/-)/Brca2(+/-) double heterozygotes

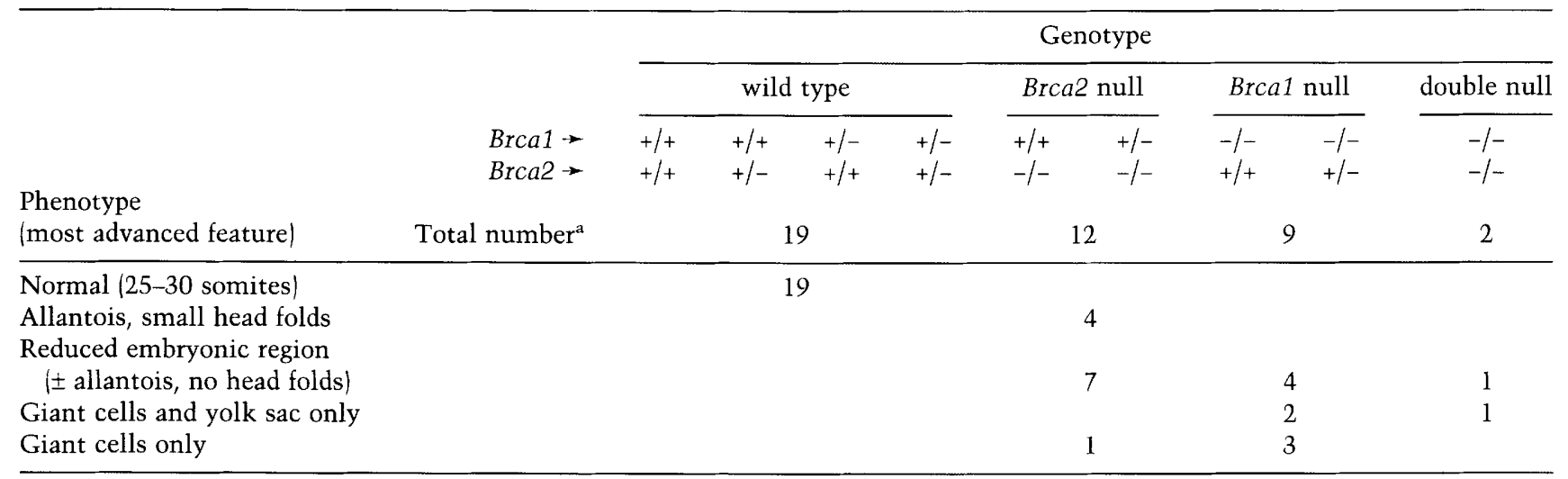

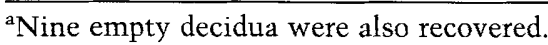

lacking both Brcal and Brca2 fell within the range of Brca1 null mutants.

Phenotype of Brcal/p53 and Brca2/p53

double nullizygotes

To ascertain genetically whether a relationship between Brcal and p53 exists, as inferred previously from molecular analyses of $\mathrm{BrCa}^{5-6}$ nullizygotes (Hakem et al. 1996), embryos from crosses producing litters that included
Brca1/p53 double nullizygotes were examined morphologically (Table 4). At E8.5, most of the embryos that possessed at least one wild-type allele of each gene or were lacking only p53 were normal and contained three to five somites, whereas one embryo in each category was less advanced. As expected, the embryos lacking only Brcal were morphologically typical for the mutation, exhibiting a greatly reduced embryonic region, an allantois, and blood islands in the yolk sac. Interestingly, all five Brca1/p53 double nullizygotes recovered at this
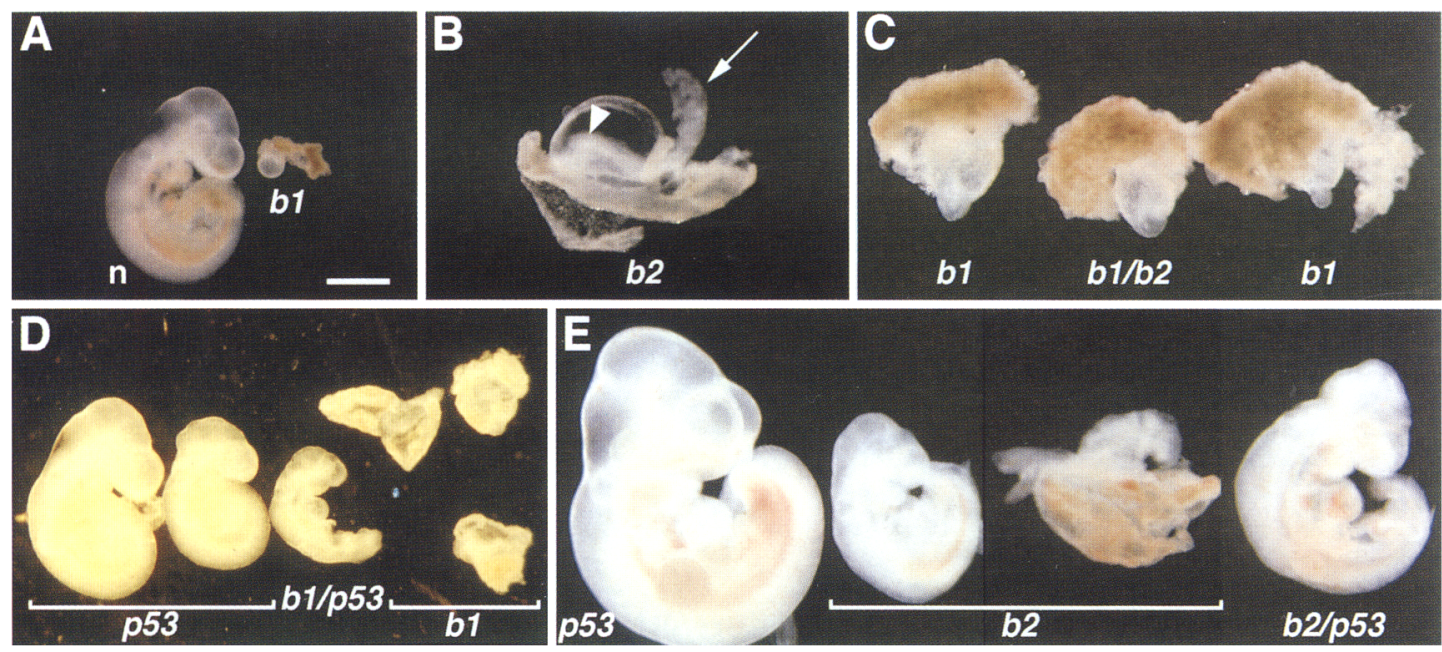

b1

Figure 4. Gross morphology of E9.5 $(A-D)$ and E10.5 (E) embryos derived from intercrosses between Brca1/Brca2 double heterozygotes $(A-C)$, between $B r c a 1 / p 53$ double heterozygotes $\{D\}$, or between $B r c a 2 / p 53$ double heterozygotes and $B r c a 2(+/-) / p 53(-/-)$ mice (E). (A) Normal (double heterozygous) embryo (n) and Brca1 (b1) nullizygous mutant (heterozygous for Brca2). (B) A Brca2 (b2) nullizygous embryo (wild-type for Brca1) with a yolk sac containing blood islands. The yolk sac has been opened to reveal head-folds (arrowhead) within the expanded amnion. A well-developed allantois is indicated with an arrow. $\{C \mid$ A Brca1/Brca2 (b1/b2) double nullizgous embryo is shown in the middle and is flanked by two Brca1 nullizygotes (wild-type for Brca2) that exhibit a similar extent of development. (D) On the left are two p53 nullizygous embryos (wild-type and heterozygous for Brca1, respectively; the second embryo has open neural folds). These are compared with a Brca1/p53 (b1/p53) double nullizygous littermate, which has developed much further than any Brca1 single mutant observed. Three Brcal single mutants are shown on the right. $(E)$ The normal embryo on the left ( $p 53$ ) is a p53 nullizygote (heterozygous for Brca2). The two embryos in the middle (b2; variable phenotypes) are Brca2 nullizygotes (heterozygous for $p 53$ ). The embryo on the right is a double nullizygote (b2/p53) and exhibits exencephaly. Scale bar, 1200 $\mu \mathrm{m}(A, D, E)$ and $600 \mu \mathrm{m}(B, C)$. 
Table 4. Results of intercrosses between Brca1 $(+/-) / \mathrm{p} 53(+/-)$ double heterozygotes and of crosses between double heterozygotes and Brcal(+/-)/p53(-/-) mice

Phenotype

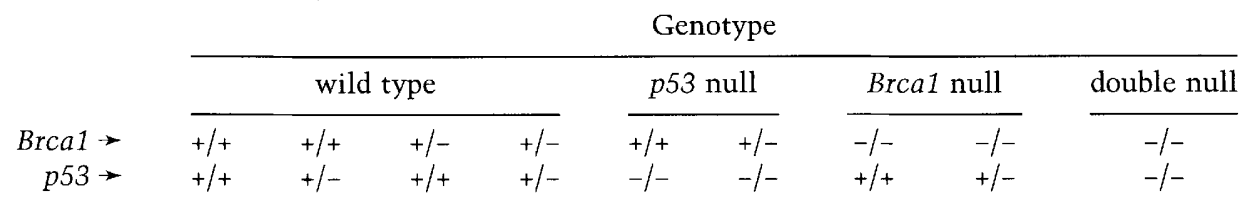

(most advanced feature)

A. $\quad$ E8.5

Total number ${ }^{\mathrm{a}}$

Normal (3-5 somites)

Normal (head fold; 0-3 somites)

Retarded (egg cylinder)

Reduced embryonic region

Yolk sac only

B. $E 9.5$

Total number ${ }^{b}$

Normal (15-20 somites)

Exencephalic $^{c}$ (15-20 somites)

Retarded (5 somites)

Abnormal head fold (1-8 somites)

Reduced embryonic region

(allantois, streak)

Reduced embryonic region

(egg cylinder)

Giant cells and yolk sac only

Giant cells only

7
5
1

1

$\begin{array}{rr}22 & 17 \\ 20 & 13 \\ 1 & 3 \\ & 1\end{array}$

11

4

4

${ }^{a}$ An additional embryo consisting of giant cells only was not genotyped. Three empty decidua were also recovered.

${ }^{\mathrm{b}}$ Two empty decidua were also recovered.

'Exencephaly (i.e., protrusion of the brain above the skull) results from failure of neural tube closure. The term is used here for embryos exhibiting open midbrain and hindbrain.

age were more advanced than their Brca1 null littermates. One of them was an egg cylinder with a constriction in the junction between the embryonic and extraembryonic regions, whereas the remaining four, although developmentally retarded in comparison with their most advanced normal littermates, appeared to be normal and had reached the head-fold stage. Two of these four embryos possessed one to three somites. At E9.5 (see Fig. 4D and Table 4), most of the embryos possessing at least one wild-type allele of each gene or lacking only p53 were normal with 15-20 somites, whereas a minority of these embryos were exencephalic (exhibiting an open and flattened midbrain and hindbrain). The occurrence of exencephaly in a subset of $p 53$ nullizygotes has been reported previously (Armstrong et al. 1995; Sah et al. 1995). We also observed a retarded p53 nullizygote with only five somites, whereas only giant cells were recovered from another embryo (heterozygous for Brca1 and wild-type for p53). All embryos lacking Brcal exhibited a range of typical abnormal phenotypes, whereas four Brca1/p53 double nullizygous mutants were further advanced than any of the embryos lacking only Brcal, although they were overtly retarded and abnormal in comparison with the controls and the p53 nullizygotes. The heart, a few somites, and large head-folds had formed in the double mutants, whereas the neural folds had a zigzag or kinky appearance. In several of the embryos the allantois was fused with the chorion.

A similar analysis was performed by examining litters of embryos that included Brca2/p53 double nullizygotes, to determine if there is also a relationship between Brca2 and p53 (Table 5). The majority of E9.5 embryos possessing at least one wild-type allele of each gene or lacking only p53 were normal with 15-25 somites, although some of them were exencephalic. Of eight embryos lacking Brca2 (all heterozygous for p53), two were smaller than their most advanced littermates, but otherwise normal with 12-20 somites, whereas the remaining six were abnormal with variable phenotypes. Two double nullizygous embryos recovered at this age were similar to the most advanced Brca2 single mutants, except that they exhibited exencephaly. At E10.5, all of the embryos with at least one wild-type allele of each gene and most of the embryos lacking only p53 were normal with more than 30 somites, whereas a few p53 nullizygotes were exencephalic. All five embryos lacking only Brca2 (heterozygous for p53) were abnormal, ranging from fairly well-formed embryos about one third the size of normal littermates to retarded, head-fold stage em- 
Table 5. Results of crosses between Brca2(+/-)/p53(+/-) double heterozygotes and Brca2(+/-)/p53(-/-) mice

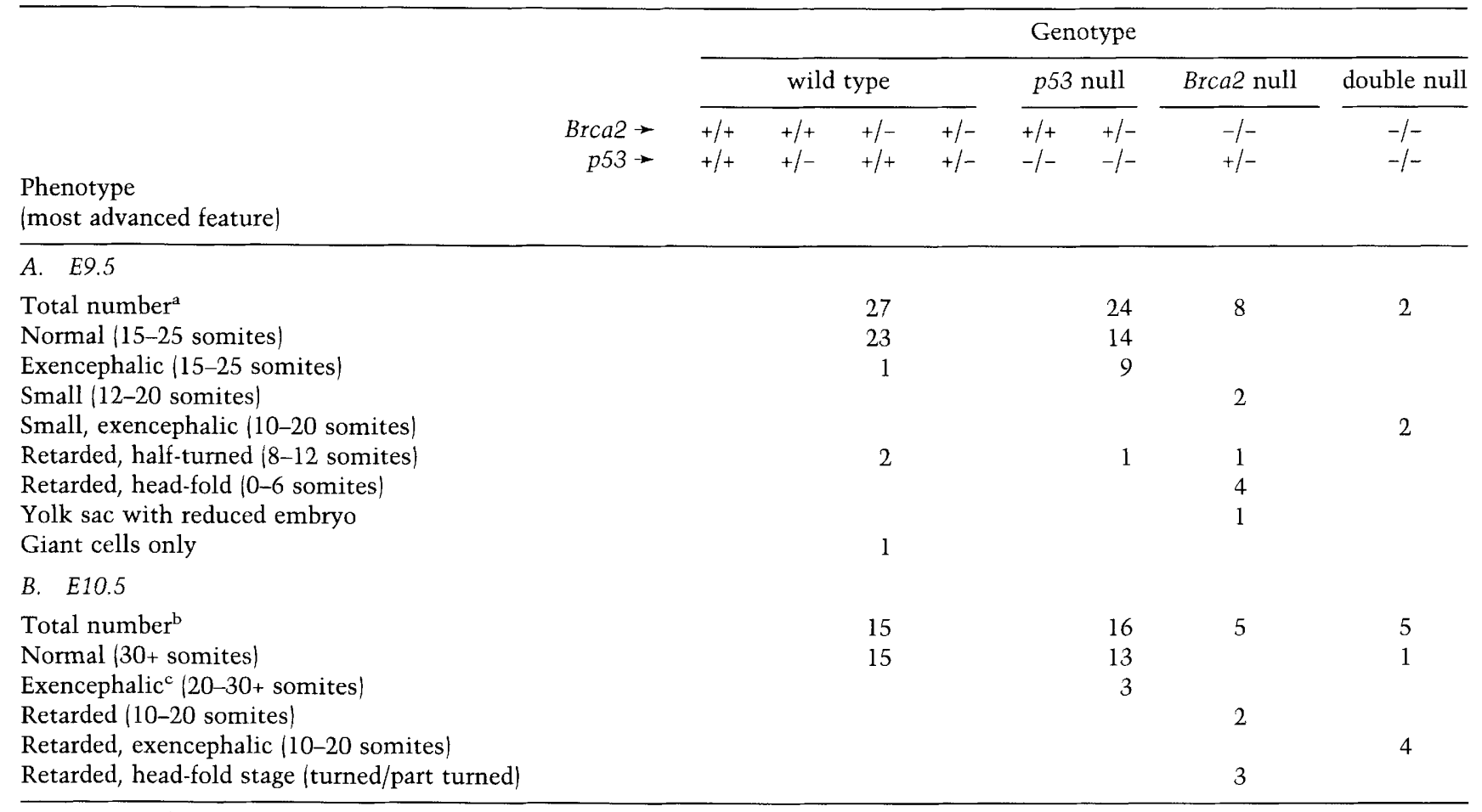

${ }^{a}$ One empty deciduum was also recovered.

${ }^{\mathrm{b}}$ Three empty decidua were also recovered.

'The frequency of excencephalic p53 null embryos was higher in this study than observed previously (Armstrong et al. 1995; Sah et al. 1995), although the sex distortion (association of exencephaly predominantly with female embryos) was not as dramatic as reported (Armstrong et al. 1995).

bryos (see Fig. 4E and Table 5). Of five double nullizygous embryos, one was indistinguishable from wild type, whereas four were similar to or somewhat more developed than the most advanced Brca2 single mutants, except that they exhibited exencephaly (see Fig. 4E and Table 5). All but one of the latter embryos had a heartbeat, one had a distended pericardium, and in two of them there was blood stasis.

\section{Discussion}

\section{Comparison of the Brcal and Brca2 null phenotypes}

It was shown previously that $\mathrm{Brca} 1$ has an indispensable role in early mouse embryogenesis (Hakem et al. 1996; Liu et al. 1996). While confirming this Brca1 function with a different deletion mutation, we showed that Brca2 is also an essential gene acting during the same period of development. Although both the Brca1 and Brca2 null mutations result in postimplantation embryonic lethality, the onset of growth and morphogenetic retardation from the lack of Brcal occurs one embryonic day earlier. Thus, all Brca1 mutants are compromised at least as early as E5.5, whereas the Brca2 nullizygotes are not distinguishable from wild type until E6.5 or later. This temporal difference in the onset of detrimental ef- fects caused by these mutations is also reflected in the development of outgrowths of cultured blastocysts. Another difference in the manifestations of the two mutations is that the range of abnormal phenotypic features detected at a particular age is much wider for Brca1 than for Brca2. In addition to their morphological variability at any given age, the Brcal mutants die at any time between E5.5 and E9.5 or shortly thereafter, assuming that most, if not all, of the observed empty decidua correspond to resorptions of mutant embryos. Nevertheless, particular Brca1 null embryos morphologically very similar to Brca2 mutants can be observed at all ages. The Brca2 nullizygotes, on the other hand, are much more uniform in morphology until E8.5, becoming variable later. Moreover, there is no indication that these mutant embryos die before E8.5, and their placental development is not as severely compromised as in Brca1 mutants.

The phenotypic characteristics of the Brca1 ${ }^{\text {ex2 }}$ mutation are overall similar to those reported for $B r c a 1^{5-6}$ nullizygotes (Hakem et al. 1996) and also for nullizygotes carrying a deletion in the $5^{\prime}$ terminal region of Brca1 exon 11 (Liu et al. 1996). However, mesoderm formation, which does occur in a subset of Brca1 nullizygotes according to our observations, was not detected in these less extensive morphological analyses, and the 
high incidence of eosinophilic masses associated with the mutants was not reported. On the other hand, these data (Hakem et al. 1996; Liu et al. 1996; this study), all obtained with $129 \times$ C57 hybrids, differ significantly from the results obtained with another Brcal gene knockout (Gowen et al. 1996). Lethality was also observed, but the phenotype was less severe, and abnormal embryos exhibiting neural tube defects developed up to E13.5. It remains to be seen whether this difference can be attributed to effects of a different genetic background that included a DBA strain component (Gowen et al. 1996). However, genetic components of the CD1 and $\mathrm{C} 3 \mathrm{H} / \mathrm{HeJ}$ strains (Hakem et al. 1996), and also of the MF1 strain (T. Ludwig, D.L. Chapman, V.E. Papaioannou, and A. Efstratiadis, unpubl.), did not alter the Brca1 null phenotype.

Although embryonic lethality was observed in all of the Brca1 mutants, a 32-year-old patient was described with inherited homozygosity for a BRCA1 mutation analyzed only at the DNA level, which would result in mature mRNA encoding a truncated protein of 900 amino acids (Boyd et al. 1995). Whether this difference reflects BRCA1 functional divergence in humans and mice remains an open question, because it is unknown whether the mutations are directly comparable (the longest peptide that could be synthesized in one of the mouse mutants would have only 300 Brcal residues; Liu et al. 1996). Nevertheless, a point of concern is that mammary tumors did not appear yet in Brca1 heterozygotes that have reached the age of 15 months. This may mean that, as in the case of $W t-1$ (Kreidberg et al. 1993), absence of Brca1 is not a tumor predisposing mutation in mice. On the other hand, very long latency, as that observed with Nf1 null mice (17-27 months; Jacks et al. 1994a) cannot be excluded.

\section{The Brca1 and Brca2 developmental pathways}

The temporal overlap of Brca1 and Brca2 gene actions, the predominant features of growth retardation and dysmorphogenesis that the two phenotypes share, and the observations made with Brca1/Brca2 double mutants raise the possibility of a relationship between the functions served by the two genes. Consistent with this hypothesis, the spatial and temporal pattern of Brca2 expression during mouse embryonic development and in adult tissues is strikingly similar to that of $\mathrm{BrCa} 1$ (Connor et al. 1997; and data cited by Rajan et al. 1996). Moreover, $B R C A 1$ and $B R C A 2$ are similarly induced in a cell cycle-dependent fashion at the $G_{1} / S$ boundary $/ Y$. Chen et al. 1996; Gudas et al. 1996; Vaughn et al. 1996a,b; Rajan et al. 1996) and both mRNAs are coordinately elevated by estrogen in breast cancer cell lines (Spillman and Bowcock 1996). This apparently coordinate regulation suggests that similar control mechanisms may be involved. Interestingly, a sequence comparison between the $B R C A 1$ and $B R C A 2$ promoter regions led to the identification of two homologous segments with similar spacing upstream from the transcriptional start sites that are conserved between human, mouse, and rat DNA (cited by Vaughn et al. 1996b). Finally, it seems hardly coincidental that both genes encode suppressors of mammary tumors, although the differences between $B R C A 1$ and $B R C A 2$ germ-line mutations in the manifestation of ovarian, pancreatic, and male breast cancers cannot be ignored.

The relatively low frequency of obtaining double mutants $(1 / 16)$ allowed us to examine only two Brca1) Brca2 nullizygotes thus far. Nevertheless, although interpreting these results with caution, we believe that at least some tentative conclusions can be reached by considering that detection of double nullizygotes was possible at the advanced age of E9.5, and that their phenotype fell within the range of Brca1 single mutants. Thus, the Brca1 mutation could be epistatic over the Brca2 mutation. A mutation is defined as epistatic over another, when the phenotypes of the single mutants differ from each other and from the wild-type, but the double mutant resembles phenotypically one of the single mutants (see Avery and Wasserman 1992). Although this relationship does not imply an interaction between pathways, we favor a model postulating that the Brca1 and Brca2 pathways are linked and may be overlapping to some degree. The competing hypothesis that the two pathways are parallel and functionally completely independent cannot be excluded, but appears to be less likely. Had that been the case, the double nullizygotes should have exhibited additive effects of the mutations, as they are both associated with growth retardation.

Interestingly, examination of seven grade 3 infiltrating ductal breast carcinomas from members of a breast/ovarian cancer family known to carry a BRCA1 mutation indicated that five of these tumors also exhibited $\mathrm{LOH}$ in the region of the BRCA2 locus (Kelsell et al. 1996). An independent report described the case of a patient diagnosed with a grade 3 ductal breast carcinoma and ovarian adenocarcinoma that were associated with germ-line mutations in both BRCA1 and BRCA2 (Ramus et al. 1997). Concordant LOH in the regions of both the $B R C A 1$ and $B R C A 2$ loci was also observed in 21 of 45 tumors of similar grade from sporadic breast cancer cases, whereas such an association was absent from grade 1 and 2 ductal carcinomas (Kelsell et al. 1996). These observations suggest a combined role for BRCA1 and BRCA2 in the tumorigenic pathway of grade 3 breast tumors.

\section{Functional relationships between Brca1 or Brca2 and p53}

It was shown previously that $m d m 2$ null embryos lacking a negative regulator of $\mathrm{p} 53$ activity die before gastrulation, but are completely rescued in a p53 null background (Jones et al. 1995; Montes de Oca Luna et al. 1995). Because inhibition of cell-cycle progression and promotion of apoptosis are included among the many diverse functions of p53 (for review, see Gottlieb and 
Oren 1996; Bates and Vousden 1996; Levine 1997; Hansen and Oren 1997), the lethality of the mdm2 single mutants, which temporally coincides with an abrupt increase in cell-cycle rate at E5.5-E6.0 (Snow 1977), was attributed to their inability to down-regulate p53, resulting in growth arrest (Jones et al. 1995; Montes de Oca Luna et al. 1995). This interpretation is consistent with observations indicating that excessive p53 activity causes severe abnormalities (see, e.g., Godley et al. 1996), in contrast to the lack of p53 that does not usually perturb development, with the exception of some mutants exhibiting exencephaly (Armstrong et al. 1995; Sah et al. 1995; this study).

Molecular analyses of $B r C a 1^{5-6}$ nullizygous embryos (Hakem et al. 1996) indicated that the level of p53 transcripts remained unaffected. However, an increase in p53 activity was not excluded, because the expression of the gene encoding one of the downstream effectors of $\mathrm{p} 53$, the 21 cyclin-dependent kinase inhibitor, was increased significantly with parallel reduction of $m d m 2$ transcript levels. In addition, BrdU incorporation assays showed that the mutant-to-control ratio of the percentage of labeled nuclei in the epiblast was reduced (Hakem et al. 1996; Liu et al. 1996), suggesting slow progression through the cell cycle. The Brca2 nullizygotes that we examined also exhibited a decreased proliferative ability as assayed by BrdU labeling.

However, the Brca1 and Brca2 mutants differ significantly in phenotypic features from $m d m 2$ nullizygotes according to our data, and as our genetic analysis demonstrated their development is shifted to more advanced stages when p53 is absent, but complete rescue of the mutations does not occur. The results were clear-cut in the case of Brca1/p53 double mutants, which did not overlap phenotypically with the severely retarded Brca1 single mutants, whereas the impact of the Brca2 mutation in the absence of p53 was ameliorated to various degrees. Thus, one of the Brca2/p53 double nullizygotes was indistinguishable from wild type, whereas others were similar to or further developed than the most advanced Brca2 single mutants.

Interestingly, the early embryonic lethal phenotype of embryos nullizygous for the mouse rad51 gene, which encodes a homolog of the Escherichia coli RecA and yeast ScRad51 proteins involved in recombinational repair of double-strand breaks in DNA, was also partially ameliorated in a $p 53$ null background (Lim and Hasty 1996). Wild-type p53 forms complexes with human Rad51 (hRad51) in vivo and is able to inhibit RecA activities in vitro (Stürzbecher et al. 1996). hRad51, which apparently participates in a complex of RNA polymerase II (Maldonado et al. 1996), was shown recently to interact with BRCAl in vitro and to co-localize with BRCAl in nulcear foci of cultured cells during the $S$ phase implying a functional relationship that could be related to the maintenance of genome integrity (Scully et al. 1997). It remains to be seen whether the Brcal BRCT domain, which is present in several proteins with cell-cycle checkpoint functions (Bork et al. 1997; Callebaut and Mornon 1997), interacts directly with p53, like the simi- lar motif used for p53-binding by 53BP1 (Iwabuchi et al. 1994; Bork et al. 1997).

Whatever the real mechanistic aspects of the Brcal or Brca2 connections to $\mathrm{p} 53$ may be, they do not appear to be related to p53-mediated apoptosis, because increased cell death is not a feature of Brca1 and Brca2 mutants (Hakem et al. 1996; Liu et al. 1996; this study). On the other hand, a p53-mediated elongation or arrest of the cell cycle in the absence of Brcal is consistent with the available evidence (Hakem et al. 1996), and a simple hypothesis postulating that Brcal (or Brca2) and p53 have antagonistic functions cannot be excluded. However, considering the interactions of Rad51 with p53 and BRCA1, and the high incidence of spontaneous DNA damage in cells (see Carr and Hoekstra 1995), an alternative conjecture is that the Brcal null phenotype is the consequence of a failure of proposed surveillance functions (Scully et al. 1997). For example, if Brcal is related to recombinational repair of double-strand breaks, which are known to initiate a p53 reponse /see Hansen and Oren 1997; Levine 1997), absence of Brcal will result in posttranscriptional induction of p53 activity causing a cell-cycle block. Even if correct, this view is most probably an oversimplification. Nevertheless, it can account for the variability in growth retardation and dysmorphogenesis characterizing the Brca1 null phenotype, considering that spontaneous DNA damage should be occurring stochastically within a range of severity. This would result in various degrees of proliferative arrest affecting differrentially growth and also patterning by variable impairment of the orderly sequence of morphogenetic events. When both Brcal and p53 are absent, however, damaged cells could continue to proliferate for some time, and embryonic death would be shifted to a later developmental stage.

The absence of functional BRCA1 or BRCA2 in tumors on one hand, and the Brcal and Brca2 gene knockouts in mouse embryos on the other, appear paradoxically to exert opposite effects on cell proliferation. In particular, BRCA1-associated breast cancers were found to be highly proliferating tumors (Eisinger et al. 1996), whereas the level of BRCA1 mRNA appeared to be markedly decreased during the transition from sporadic breast carcinoma in situ to invasive cancer (Thompson et al. 1995|. Moreover, overexpression of BRCA1 inhibited the proliferation of breast and ovarian cell lines, whereas transfer of $B R C A 1$ into MCF-7 breast cancer cells inhibited their ability to form tumors in nude mice (Holt et al. 1996). Conversely, antisense oligonucleotidemediated reduction in BRCA1 expression increased the proliferation of mammary epithelial cells (Thompson et al. 1995). Therefore, it was thought that BRCA1 is involved in negative regulation of tumor cell proliferation. In contrast, a positive role of Brcal in cell growth control was proposed for mouse embryos (Hakem et al. 1996). However, from the point of view of the hypothetical scenario described above, this paradox may be more apparent than real and related to epiphenomena. The inability to monitor DNA damage would be manifested as hypoproliferation in Brca1 mutant embryos, whereas in tu- 
mors, it could allow accumulation of additional mutations promoting abnormal overgrowth, if the lack of BRCAl is involved in tumor progression, rather than initiation, as proposed (Scully et al. 1997).

\section{Comparison of the Brcal and pnlf5 mutant phenotypes}

Comparison of our data with the features of other mouse mutations resulting in postimplantation lethality isee Copp 1995) showed that the Brca1 nullizygous embryos exhibit a striking resemblance with the early embryonic lethal phenotype of homozygotes carrying the radiationinduced deletion mutation $5 \mathrm{RD} 300 \mathrm{H}$ or $\mathrm{se}^{l}$ (short-ear lethal; Russell 1971; Dunn 1972) that includes the se (short-ear) locus encoding Bmp-5 (bone morphogenetic protein 5; Kingsley et al. 1992) on mouse chromosome 9. The locus associated with the early embryonic lethality identified by the $s e^{I}$ mutation is designated pnlf5 (prenatal lethal function 5; Imai and Kingsley 1994). The histological appearance of the pnlf5 nullizygotes at around E8.0, which exhibit large giant cells, a severely reduced embryonic region, and an ectoplacental cavity filled with a solid mass of extraembryonic ectodermal cells (Dunn 1972), is almost indistinguishable in morphology from Brca1 mutants at E8.5. The segment of mouse chromosome 9 where pnlf5 resides is syntenic with the q12-13 region of human chromosome 6 (DeBry and Seldin 1996). Interestingly, the presence of a tumor suppressor gene at $6 \mathrm{q} 13$ has been postulated because of a high incidence of allelic imbalance in this region in malignant breast tumors (Orphanos et al. 1995).

\section{Materials and methods}

\section{Construction of replacement vectors}

To isolate mouse clones carrying portions of the Brca1 and $B r c a 2$ genes, we screened a genomic $\lambda$ phage library from strain $129 /$ Sv using probes of corresponding human BRCA1 (exons 1-6) and $B R C A 2$ (exon 11) sequences that were synthesized, respectively, by reverse transcription (RT)-PCR from HeLa cell poly $(\mathrm{A})^{+}$RNA and by PCR from DNA of a BRCA2 cosmid clone (see Fischer et al. 1996). Eight Brca1 overlapping clones containing exons $1-11$ and four Brca2 overlapping clones containing exon 11 were identified and characterized by restriction mapping, Southern analysis and DNA sequencing. Southern analysis of mouse genomic DNA indicated that, as in humans, the Brca2 gene is unique in mice (see also Connor et al. 1997; Sharan and Bradley 1997). From subcloned fragments of the isolated clones, targeting vectors (Fig. 5) were constructed in several steps. In each construct, we included a neomycin resistance gene (neo) cassette (1.1 kb from plasmid pMC1neo polyA), for positive selection using the antibiotic G418, and a thymidine kinase $(t \mathrm{k})$ gene cassette ( $1.85 \mathrm{~kb}$ from plasmid $\mathrm{pMCltk}$ ), to enrich for targeted clones by negative selection with gancyclovir. Both of these cassettes were placed in the same transcriptional orientation as that of the gene promoters. The final Brca1 product consisted of a $5^{\prime}$ genomic fragment $(2.1 \mathrm{~kb})$; the neo cassette replacing a $0.7-\mathrm{kb}$ genomic fragment containing exon 2; a downstream genomic fragment $(7.2 \mathrm{~kb})$; and the $t \mathrm{k}$ cassette. The final Brca2 vector consisted of a $5^{\prime}$ genomic fragment 2.5

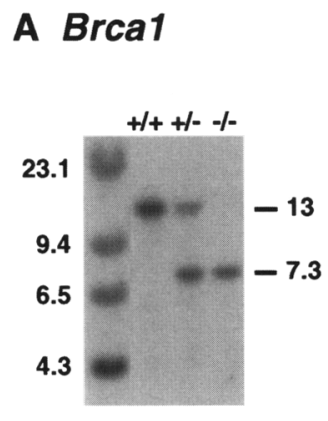

(c)

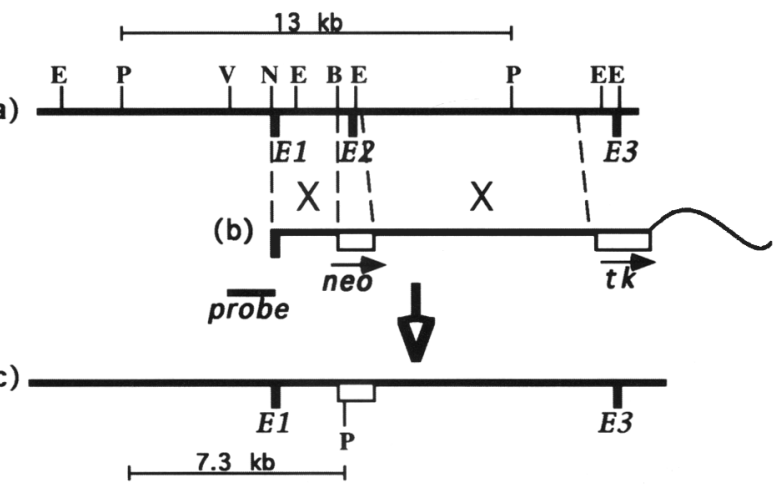

\section{B Brca2}

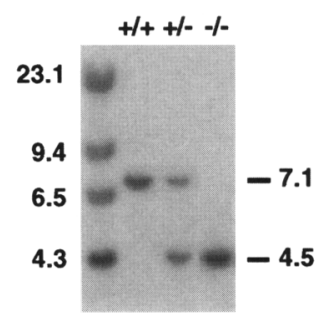

(d)

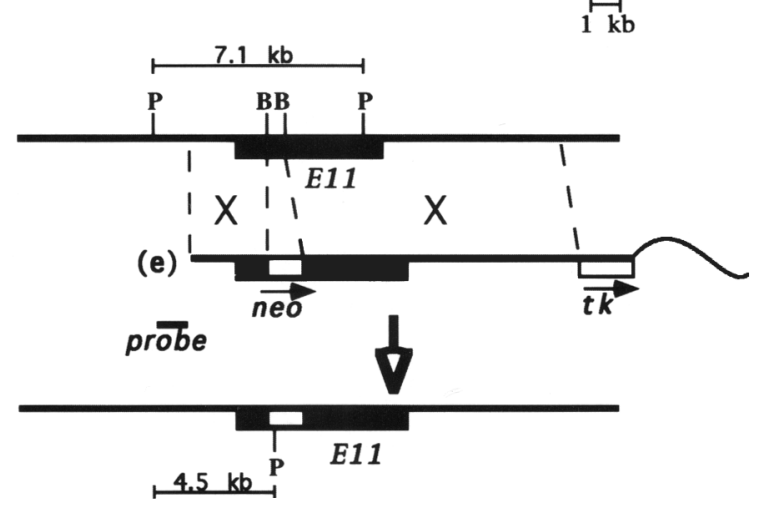

Figure 5. Targeting of the Brcal and Brca2 genes. Restriction maps in the region of the first three Brca1 exons (E1-E3; solid rectangles) $(a \mid$, and in the region of Brca2 exon $11(E 11)(d)$. The restriction sites are: EcoRI (E), PstI (P), EcoRV (V), $\operatorname{NotI}(\mathrm{N})$, and BamHI (B). Diagrams of the targeting constructs used for gene disruption by homologous recombination /denoted by large X symbols) are shown for Brca1 $(b)$ and Brca2 $(e)$. The transcriptional orientations of the neo and $t k$ genes are indicated with arrows. The wavy line represents plasmid vector sequence. The structures of the Brca1 and Brca2 loci after targeting (large open arrow) are shown in $c$ and $f$, respectively. Examples of genotyping of E9.5 embryo DNA by PstI digestion are shown in autoradiograms of Southern blots. The sizes of fragments corresponding to wild-type and mutated alleles that are hybridizing with the indicated probes are correlated with the diagrams. The size markers are HindIII fragments of phage $\lambda$ DNA. 
$\mathrm{kb}$; the neo cassette replacing a $0.52-\mathrm{kb}$ fragment within exon 11 ; a downstream genomic fragment $(9.1 \mathrm{~kb})$; and the $t k$ cassette.

Gene targeting and blastocyst injections

Linearized vector DNA was introduced by electroporation into passage $12129 /$ Sv ES cells (CCE-33) grown on mitomycin Ctreated, G418-resistant STO cell feeder layers, and after drug selection, DNA of resistant clones was analyzed by Southern blotting using a neo probe and also probes with sequences corresponding to genomic DNA upstream from the 5 ' region of homology in the vectors (Fig. 5).

To generate chimeras, cells of targeted clones were microinjected into host blastocysts from the C57BL/6 1 mouse strain that were transferred into the uteri of pseudopregnant females. Chimeras were mated with C57BL/6 females, and germ-line transmission was verified by Southern analysis. Three independent targeted clones for Brca1 and two for Brca2 yielded germline transmitters. $F_{1}$ heterozygous animals were intercrossed and $\mathrm{F}_{2}$ offsprings were analyzed by Southern blotting. Heterozygous males for Brca1 were also crossed with females heterozygous for Brca2 or heterozygous for $p 53$, to derive double heterozygotes, which were subsequently intercrossed. The $p 53 \mathrm{mu}-$ tant mice (Jacks et al. 1994b) were obtained from the Jackson Labs.

\section{Genotyping}

For genotyping by Southern analysis with $5^{\prime}$ flanking and/or neo cassette probes, DNA was prepared from yolk sacs, whole E9.5 and E10.5 embryos or the tail tip of two-week-old mice. Embryos were sexed by Southern blotting using a $\mathrm{Y}$ chromosome-specific probe (Bishop and Hatat 1987). For genotyping of embryos from stained histological sections by PCR amplification, we used a protocol that we developed previously (see Zeitlin et al. 1995). To identify Brca1 mutants we used the oligonucleotides: (1) Brca1 forward primer 5'-GGACGGCAGATAAATCCATTTCTTCC-3' (near the 3' end of intron 1); (2) Brca1 reverse primer $5^{\prime}$-GGTACAAAGCCAGTGTGGGTTACATG$3^{\prime}$ (within exon 2); (3) neo forward primer 5'-GGAATGTTTCCACCCAATGTCGAGC-3'; and (4) neo reverse primer 5'-CATCAGAGCCGATTGTCTGTTG- $3^{\prime}$. The Brca1 primers generate a 169-bp amplification product from wild-type and heterozygous embryos, whereas the neo primers amplify a 266-bp fragment in heterozygous and homozygous embryos. To identify Brca2 mutants we used the primers 5'-GGGAACAGTGATTGTTCAGACAAATGGTC-3' (forward) and 5'-GCTGTGATCTGTCTGACCTACAGAGG-3' (reverse) flanking the segment of exon 11 that is deleted in the mutants. Amplification of the wild-type allele results in a 589-bp product, whereas the product of the targeted allele is $1.2 \mathrm{~kb}$, because of the insertion of the neo cassette.

\section{Histological analyses}

Whole uteri at E5.5 and decidua dissected at E6.5, E7.5, and E8.5 were fixed overnight in $4 \%$ paraformaldehyde, $0.1 \mathrm{M}$ phosphate buffer (pH 7.3), washed for $24 \mathrm{hr}$ at $4^{\circ} \mathrm{C}$ in $0.25 \mathrm{M}$ sucrose, $0.2 \mathrm{M}$ glycine, $0.1 \mathrm{M}$ phosphate buffer $(\mathrm{pH} 7.3)$, dehydrated, and embedded in paraffin. Paraffin blocks were sectioned at $6 \mu \mathrm{m}$ and stained with hematoxylin and eosin.

\section{BrdU labeling of embryos}

Labeling of cells in the $\mathrm{S}$ phase with $\mathrm{BrdU}$ was performed as described (Hayashi et al. 1988). BrdU (100 $\mu \mathrm{g} /$ gram of body weight) was injected intraperitoneally into pregnant females at E6.5 and E7.5, which were sacrificed $1 \mathrm{hr}$ after the injection. The decidua were dissected, fixed in $4 \%$ paraformaldehyde and processed for immunohistochemistry. Sections were incubated with a monoclonal anti-BrdU antibody (Becton-Dickinson) at a 1:20 dilution, and staining was performed as described (Mishina et al. 1995).

\section{In situ hybridization}

Whole-mount in situ hybridization was performed as described (Wilkinson 1992), using digoxigenin-labeled antisense RNA probes for Brachyury and Oct-4 that were synthesized, respectively, from linearized plasmids pME685 (Herrmann 1991) and Oct-4Stu462 (Schöler et al. 1990).

\section{Culture of blastocyst outgrowths}

Pregnant females from heterozygous intercrosses were sacrificed at E3.5, and embryos were collected by flushing the uteri. Following removal of the zona pellucida with acidified Tyrode's solution, blastocysts were cultured individually in 24-well plates in Dulbecco's modified Eagle medium (DMEM) supplemented with $20 \%$ fetal calf serum (FCS) at $37^{\circ} \mathrm{C}$ in $5 \% \mathrm{CO}_{2}$ in air, and examined and photographed daily for four to five days. At the end of the experiment, the tissue was scraped off the dish, and DNA was extracted for genotyping by PCR.

\section{Acknowledgments}

We thank Hanina Hibshoosh for help with tumor pathology; Hans Schöler and Catherine Ovitt for probes; Yuji Mishina and Richard Behringer for experimental protocols; David Kingsley for discussions; and Karen Liu and Peter Rodriguez for excellent technical assistance. This work was supported by grants DK49002 from the National Institutes of Health and 9625 from the Susan G. Komen Breast Cancer Foundation to A.E., and by grant DAMD 17-96-1-6090 from the Department of the Army to V.E.P. Seed funding to initiate the Brca1 project was provided by the Columbia Innovation Enterprise and the Columbia Cancer Center Breast Cancer Research Program supported by the National Cancer Institute.

The publication costs of this article were defrayed in part by payment of page charges. This article must therefore be hereby marked "advertisement" in accordance with 18 USC section 1734 solely to indicate this fact.

\section{References}

Abel, K.J., J. Xu, G.-Y. Yin, R.H. Lyons, M.H. Meisler, and B.L. Weber. 1995. Mouse Brca1: Isolation, sequence analysis and identification of evolutionary conserved domains. Hum. Mol. Genet. 12: 2265-2273.

Armstrong, J.F., M.H. Kaufman, D.J. Harrison, and A.R. Clarke. 1995. High-frequency developmental abnormalities in p53deficient mice. Curr. Biol. 5: 931-936.

Avery, L. and S. Wasserman. 1992. Ordering gene function, the interpretation of epistasis in regulatory hierarchies. Trends Genet. 8: 312-316.

Bates, S. and K.H. Vousden. 1996. p53 in signaling checkpoint arrest or apoptosis. Curr. Opin. Genet. Dev. 6: 12-19.

Bennett, M.L., A. Haugen-Strano, C. Cochran, H.A. Brownlee, F.T. Fiedorek, and R.W. Wiseman. 1995. Isolation of the mouse homologue of BRCAl and genetic mapping to mouse chromosome 11. Genomics 29: 576-581. 
Bingell, G., G. Micklem, M.R. Stratton, A. Ashworth, and R. Wooster. 1997. The BRC repeats are conserved in mammalian BRCA2 proteins. Hum. Mol. Genet. 6: 53-58.

Bishop, C.E. and D. Hatat. 1987. Molecular cloning and sequence analysis of a mouse Y chromosome RNA transcript expressed in the testis. Nucleic Acids Res. 15: 2959-2969.

Bork, P., N. Blomberg, and M. Nigles. 1996. Internal repeats in the BRCA2 protein sequence. Nature Genet. 13: 22-23.

Bork, P., K. Hofmann, P. Bucher, A.F. Neuwald, S.F. Altschul, and E.V. Koonin. 1997. A superfamily of conserved domains in DNA damage-responsive cell cycle checkpoint proteins. FASEB I. 11: 68-76.

Boyd, M., F. Harris, R. McFarlane, H.R. Davidson, and D.M. Black. 1995. A human BRCA1 gene knockout. Nature 375: 541-542.

Brown, M.A., C.-F. Xu, H. Nicolai, B. Griffiths, J.A. Chambers, D. Black, and E. Solomon. 1996. The $5^{\prime}$ end of the BRCA1 gene lies within a duplicated region of human chromosome 17q21. Oncogene 12: 2507-2513.

Callebaut, I. and J.-P. Mornon. 1997. From BRCA1 to RAP1: A widespread BRCT module closely associated with DNA repair. FEBS Lett. 400: 25-30.

Cannon-Albright, L.A. and M.H. Skolnick. 1996. The genetics of familial breast cancer. Semin. Oncol. 23(Suppl. 2): 1-5.

Carr, A.M. and M.F. Hoekstra. 1995. The cellular responses to DNA damage. Trends Cell Biol. 5: 32-40.

Chapman, M.S. and I.M. Verma. 1996. Transcriptional activation by BRCA1. Nature 382: 678-679.

Chen, C.-F., S. Li, Y. Chen, P.-L. Chen, Z.D. Sharp, and W.-H. Lee. 1996. The nuclear localization sequences of the BRCA1 protein interact with the importin-a subunit of the nulcear transport signal receptor. J. Biol. Chem. 271: 32863-32868.

Chen, Y., A.A. Farmer, C.-F. Chen, D.C. Jones, P.-L. Chen, and W.-H. Lee. 1996. BRCAl is a $220-\mathrm{kDa}$ nuclear phosphoprotein that is expressed and phosphorylated in a cell cycledependent manner. Cancer Res. 56: 3168-3172.

Claus, E.B., N. Risch, and W.D. Thompson. 1991. Genetic analysis of breast cancer in the cancer and steroid hormone study. Am. J. Hum. Genet. 48: 232-242.

Collins, N., R. McManus, R. Wooster, J. Mangion, S. Seal, S.R. Lakhani, W. Ormiston, P.A. Daly, D. Ford, D.F. Easton, et al. 1995. Consistent loss of the wild type allele in breast cancers from a family linked to the BRCA2 gene on chromosome 13q12-13. Oncogene 10: 1673-1675.

Connor, F., A. Smith, R. Wooster, M. Stratton, A. Dixon, E. Campbell, T.-C. Tait, T. Freeman, and A. Ashworth. 1997. Cloning, chromosomal mapping and expression pattern of the mouse Brca2 gene. Hum. Mol. Genet. 6: 291-300.

Copp, A.J. 1995. Death before birth: Clues from gene knockouts and mutations. Trends Genet. 11: 87-93.

Couch, F.J., L.M. Farid, M.L. DeShano, S.V. Tavtigian, K. Calzone, L. Campeau, Y. Peng, B. Bogden, Q. Chen, S. Neuhausen, et al. 1996. BRCA2 germline mutations in male breast cancer cases and breast cancer families. Nature Genet. 13: $123-125$.

DeBry, R.W. and M.F. Seldin. 1996. Human/mouse homology relationships. Genomics 33: 337-351.

Dunn, G.R. 1972. Embryological effects of a minute deficiency in linkage group II of the mouse. J. Embryol. Exp. Morphol. 27: 147-154.

Easton, D.F., D. Ford, and J. Peto. 1993. Inherited susceptibility to breast cancer. Cancer Surv. 18: 95-113.

Easton, D.F., D. Ford, D.T. Bishop, and the Breast Cancer Linkage Consortium. 1995. Breast and ovarian cancer incidence in BRCA1-mutation carriers. Am. I. Hum. Genet. 56: 265271 .
Eisinger, F., D. Stoppa-Lyonnet, M. Longy, F. Kerangueven, T. Noguchi, C. Bailly, A. Vincent-Salomon, J. Jacquemier, D. Birnbaum, and H. Sobol. 1996. Germ line mutation of BRCA1 affects the histoprognostic grade in hereditary breast cancer. Cancer Res. 56: 471-474.

Feunteun, I. and G.M. Lenoir. 1996. BRCA1, a gene involved in inherited predisposition to breast and ovarian cancer. Biochim. Biophys. Acta 1242: 177-180.

Fischer, S.G., E. Cayanis, M. Bonaldo, A.M. Bowcock, L.L. Deaven, I.S. Edelman, T. Gallardo, S. Kalachikov, L. Lawton, J.L. Longmire, et al. 1996. A high-resolution annotated physical map of the human chromosome 13q12-13 region containing the breast cancer susceptibility locus BRCA2. Proc. Natl. Acad. Sci. 93: 690-694.

Freemont, P.S. 1993. The RING finger, a novel protein sequence motif related to the zinc finger. Ann. N.Y. Acad. Sci. 684: 174-192.

Gayther, S.A., W. Warren, S. Mazoyer, P.A. Russell, P.A. Harrington, M. Chiano, S. Seal, R. Hamoudi, E.J. van Rensburg, A.M. Dunning et al. 1995. Germline mutations of the $B R C A 1$ gene in breast and ovarian cancer families provide evidence for a genotype-phenotype correlation. Nature Genet. 11: 428-433.

Godley, L.A., J.B. Kopp, M. Eckhaus, J.J. Paglino, J. Owens, and H.E. Varmus. 1996. Wild-type p53 transgenic mice exhibit altered differentiation of the ureteric bud and possess small kidneys. Genes \& Dev. 10: 836-850.

Goggins, M., M. Schutte, J.L. Lu, C.A. Moskaluk, C.L. Weinstein, G.M. Petersen, C.J. Yeo, C.E. Jackson, H.T. Lynch, R.H. Hruban, and S.E. Kern. 1996. Germline BRCA2 gene mutations in patients with apparently sporadic pancreatic carcinomas. Cancer Res. 56: 5360-5364.

Gottlieb, T.M. and M. Oren. 1996. p53 in growth control and neoplasia. Biochim. Biophys. Acta 1287: 77-102.

Gowen, L.C., B.L. Johnson, A.M. Latour, K.K. Sulik, and B.H. Koller. 1996. Brca1 deficiency results in early embryonic lethality characterized by neuroepithelial abnormalities. Nature Genet. 12: 191-194.

Gudas, J.M., T. Li, H. Nguyen, D. Jensen, F.J. Rauscher, and K.H. Cowan. 1996. Cell cycle regulation of BRCA1 messenger RNA in human breast epithelial cells. Cell Growth Differ. 7: 717-723.

Hakem, R., J.L. de la Pompa, C. Sirard, R. Mo, M. Woo, A. Hakem, A. Wakeham, I. Potter, A. Reitmair, F. Billia, E. Firpo, C.C. Hui, J. Roberts, J. Rossant, and T.W. Mak. 1996. The tumor suppressor gene Brcal is required for embryonic cellular proliferation in the mouse. Cell 85: 1009-1023.

Hansen, R. and M. Oren. 1997. p53; from inductive signal to cellular effect. Curr. Opin. Genet. Dev. 7: 46-51.

Hayashi, Y., M. Koike, M. Matsutani, and T. Hoshino. 1988. Effects of fixation time and enzymatic digestion on immunohistochemical demonstration of bromodeoxyuridine in formalin-fixed, paraffin-embedded tissues. I. Histochem. Cytochem. 36: 511-514.

Herrmann, B.G. 1991. Expression pattern of the Brachyury gene in whole-mount $T^{\text {Wis }} / T^{\text {Wis }}$ mutant embryos. Development 113: 913-917.

Holt, J.T., M.E. Thompson, C.I. Szabo, C. Robinson-Benion, C.L. Arteaga, M.-C. King, and R.A. Jensen. 1996. Growth retardation and tumour inhibition by BRCA1. Nature Genet. 12: 298-302.

Imai, K. and D.M. Kingsley. 1994. Mouse chromosome 9. Mamm. Genome 5: S139-S153.

Iwabuchi, K., P.L. Bartel, B. Li, R. Marraccino, and S. Fields. 1994. Two cellular proteins that bind to wild-type but not mutant p53. Proc. Nat1. Acad. Sci. 91: 6098-6102. 
Jacks, T., T.S. Shih, E.M. Schmitt, R.D. Bronson, A. Bernards, and R.A. Weinberg. 1994a. Tumorigenic and developmental consequences of a targeted Nf1 mutation in the mouse. $\mathrm{Na}$ ture Genet. 7: 353-361.

Jacks, T., L. Remington, B.O. Williams, E.M. Schmitt, S. Halachmi, R.T. Bronson, and R.A. Weinberg. 1994b. Tumor spectrum analysis in p53-mutant mice. Curr. Biol. 4: 1-7.

Johannsson, O., E.A. Ostermeyer, S. Håkansson, L.S. Friedman, U. Johansson, G. Sellberg, K. Brøndum-Nielsen, V. Sele, H. Olsson, M.-C. King, and A. Borg. 1996. Founding BRCA1 mutations in hereditary breast and ovarian cancer in Southern Sweden. Am. I. Hum. Genet. 58: 441-450.

Jones, S.N., A.E. Roe, L.A. Donehower, and A. Bradley. 1995. Rescue of embryonic lethality in Mdm2-deficient mice by absence of p53. Nature 378: 206-208.

Kelsell, D.P., N.K. Spurr, D.M. Barnes, B. Gusterson, and D.T. Bishop. 1996. Combined loss of $B R C A 1 / B R C A 2$ in grade 3 breast carcinomas. Lancet 347: 1554-1555.

Kingsley, D.M., A.E. Bland, J.M. Grubber, P.C. Marker, L.B. Russell, N.G. Copeland, and N.A. Jenkins. 1992. The mouse short ear skeletal morphogenesis locus is associated with defects in a bone morphogenetic member of the TGF $\beta$ superfamily. Cell 71: 399-410.

Koonin, E.V., S.F. Altschul, and P. Bork. 1996. [BRCA1 protein products], functional motifs. Nature Genet. 13: 266-268.

Kreidberg, J.A., H. Sariola, J.M. Loring, M. Maeda, J. Pelletier, D. Housman, and R. Jaenisch. 1993. WT-1 is required for early kidney development. Cell 74: 679-691.

Lancaster, J.M., R. Wooster, J. Mangion, C.M. Phelan, C. Cochran, C. Gumbs, S. Seal, R. Barfoot, N. Collins, G. Bingell, et al. 1996. BRCA2 mutations in primary breast and ovarian cancers. Nature Genet. 13: 238-240.

Lane, T.F., C. Deng, A. Elson, M.S. Lyu, C.A. Kozak, and P. Leder. 1995. Expression of BrCa1 is associated with terminal differentiation of ectodermally and mesodermally derived tissues in mice. Genes \& Dev. 9: 2712-2722.

Levine, A.J. 1997. p53, the cellular gatekeeper for growth and division. Cell 88: 323-331.

Lim, D.-S. and P. Hasty. 1996. A mutation in mouse rad51 results in an early embryonic lethal that is suppressed by a mutation in p53. Mol. Cell. Biol. 16: 7133-7143.

Liu, C.-Y., A. Flesken-Nikitin, S. Li, Y. Zeng, and W.-H. Lee. 1996. Inactivation of the mouse Brca1 gene leads to failure in the morphogenesis of the egg cylinder in early postimplantation development. Genes \& Dev. 10: 1835-1843.

Maldonado, E., R. Shiekhattar, M. Sheldon, H. Cho, R. Drapkin, P. Rickert, E. Lees, C.W. Anderson, S. Linn, and D. Reinberg. 1996. A human RNA polymerase II complex associated with SRB and DNA-repair proteins. Nature 381: 86-89.

Marcus, J.N., P. Watson, D.L. Page, S.A. Narod, G.M. Lenoir, P. Tonin, L. Linder-Stephenson, G. Salerno, T.A. Conway, and H.T. Lynch. 1996. Hereditary breast cancer, pathobiology, prognosis, and $B R C A 1$ and $B R C A 2$ gene linkage. Cancer 77: 697--709.

Miki, Y., J. Swensen, D. Shattuck-Eidens, P.A. Futreal, K. Harshman, S. Tavtigian, Q. Liu, C. Cochran, L.M. Bennett, W. Ding, et al. 1994. A strong candidate for the breast and ovarian cancer susceptibility gene BRCA1. Science 266: 6671.

Miki, Y., T. Katagiri, F. Kasumi, T. Yoshimoto, and Y. Nakamura. 1996. Mutation analysis in the BRCA2 gene in primary breast cancers. Nature Genet. 13: 245--247.

Mishina, Y., A. Suzuki, N. Ueno, and R.R. Behringer. 1995. $B m p r$ encodes a type 1 bone morphogenetic protein receptor that is essential for gastrulation during mouse embryogenesis. Genes \& Dev. 9: 3027-3037.
Monteiro, A.N.A., A. August, and H. Hanafusa. 1996. Evidence for a transcriptional activation function of BRCA1 C-terminal region. Proc. Nat1. Acad. Sci. 93: 13595-13599.

Montes de Oca Luna, R., D.S. Wagner, and G. Lozano. 1995. Rescue of early embryonic lethality in $m d m$ 2-deficient mice by deletion of $p 53$. Nature 378: 203-206.

Neuhausen, S.L. and C.J. Marshall. 1994. Loss of heterozygosity in familial tumors from three BRCA1-linked kindreds. Cancer Res. 54: 6069-6072.

Neuhausen, S., T. Gilewski, L. Norton, T. Tran, P. McGuire, J. Swensen, H. Hampel, P. Borgen, K. Brown, M. Skolnick, et al. 1996. Recurrent BRCA2 6174delT mutations in Ashkenazi Jewish women affected by breast cancer. Nature Genet. 13: 126-128.

Orphanos, V., G. McGown, J.M. Boyle, and M. Santibanez-Koref. 1995. Proximal 6q, a region showing allele loss in primary breast cancer. Br. T. Cancer 71: 290-293.

Phelan, C.M., J.M. Lancaster, P. Tonin, C. Gumbs, C. Cochran, R. Carter, P. Ghadirian, C. Perret, R. Moslehi, F. Dion, et al. 1996. Mutation analysis of the $B R C A 2$ gene in 49 site-specific breast cancer families. Nature Genet. 13: 120-122.

Rajan, J.V., M. Wang, S.T. Marquis, and L.A. Ghodosh. 1996. Brca2 is coordinately regulated with Brca1 during proliferation and differentiation in mammary epithelial cells. Proc. Natl. Acad. Sci. 93: 13078-13083.

Ramus, S.J., L.S. Friedman, S.A. Gayther, B.A. Ponder, L.G. Bobrow, M. van der Looji, J. Papp, and E. Olah. 1997. A breast/ ovarian cancer patient with germline mutations in both BRCA1 and BRCA2. Nature Genet. 15: 14-15.

Rao, V.N., N. Shao, M. Ahmad, and E.S.P. Reddy. 1996. Antisense RNA to a putative tumor suppressor gene $B R C A 1$ transforms mouse fibroblasts. Oncogene 12: 523-528.

Russell, L.B. 1971. Definition of functional units in a small chromosomal segment of the mouse and its use in interpreting the nature of radiation-induced mutations. Mutat. Res. 11: $107-123$.

Sah, V.P., L.D. Attardi, G.J. Mulligan, B.O. Williams, R.T. Bronson, and T. Jacks. 1995. A subset of p53-deficient embryos exhibit exencephaly. Nature Genet. 10: 175-180.

Saurin, A.J., K.L.B. Borden, M.N. Boddy, and P.S. Freemont. 1996. Does this have a familiar RING? Trends Biochem. Sci. 21: 208-214.

Schöler, H.R., G.R. Dressler, R. Balling, H. Rohdewohld, and P. Gruss. 1990. Oct-4, a germline-specific transcription factor mapping to the mouse $t$-complex. EMBO I. 9: 2185-2195.

Schutte, M., L.T. DaCosta, S.A. Hahn, C. Moskaluk, A.T.M.S Hoque, E. Rozenblum, C.L. Weinstein, M. Bittner, P.S. Meltzer, J.M. Trent, et al. 1995. Identification by representational difference analysis of a homozygous deletion in pancreatic carcinoma that lies within the BRCA2 region. Proc. Natl. Acad. Sci. 92: 5950-5954.

Scully, R., J. Chen, A. Plug, Y. Xiao, D. Weaver, J. Feunteun, T Ashley, and D.M. Livingston. 1997. Association of BRCAl with Rad51 in mitotic and meiotic cells. Cell 88: 265-275.

Serova, O., M. Montagna, D. Torchard, S.A. Narod, P. Tonin, B. Sylla, H.T. Lynch, J. Feunteun, and G.M. Lenoir. 1996. A high incidence of BRCAl mutations in 20 breast-ovarian cancer families. Am. J. Hum. Genet. 58: 42-51.

Sharan, S.K. and A. Bradley. 1997. Murine Brca2: Sequence, map position, and expression pattern. Genomics 40: 234-241.

Sharan, S.K., M. Wims, and A. Bradley. 1995. Murine Brca1, sequence and significance for human missense mutations. Hum. Mol. Genet. 12: 2275-2278.

Smith, S.A., D.F. Easton, D.G. Evans, and B.A. Ponder. 1992. Allele losses in the region $17 \mathrm{q} 12-21$ in familial breast and ovarian cancer involve the wild-type chromosome. Nature 
Genet. 2: 128-131.

Smith, T.M., M.K. Lee, C.I. Szabo, N. Jerome, M. McEuen, M. Taylor, L. Hood, and M.-C. King. 1996. Complete genomic sequence and analysis of $117 \mathrm{~kb}$ of human DNA containing the gene BRCA1. Genome Res. 6: 1029-1049.

Snow, M.H.L. 1977. Gastrulation in the mouse: Growth and regionalization of the epiblast. J. Embryol. Exp. Morphol. 42: 293-303.

Spillman, M.A. and A.M. Bowcock. 1996. BRCA1 and BRCA2 mRNA levels are coordinately elevated in human breast cancer cells in response to estrogen. Oncogene 13: 1639-1645.

Stratton, M.R. and R. Wooster. 1996. Hereditary predisposition to breast cancer. Curr. Opin. Genet. Dev. 6: 93-97.

Stürzbecher, H.-W., B. Donzelmann, W. Henning, U. Knippschild, and S. Buchhop. 1996. p53 is linked directly to homologous recombination processes via RAD51/RecA protein interaction. EMBO /. 15: 1992-2002.

Szabo, C.I. and M.-C. King. 1995. Inherited breast and ovarian cancer. Hum. Mol. Genet. 4: 1811-1817.

Tavtigian, S.V., J. Simard, J. Rommens, F. Couch, D. ShattuckEidens, S. Neuhausen, S. Marajver, S. Thorlacius, K. Offit, D. Stoppa-Lyonnet, et al. 1996. The complete BRCA2 gene and mutations in chromosome 13q-linked kindreds. Nature Genet. 12: 333-337.

Teng, D.H.-F., R. Bogden, J. Mitchell, M. Baumgard, R. Bell, S. Berry, T. Davis, P.C. Ha, R. Kehrer, S. Jammulapati, et al. 1996. Low incidence of BRCA2 mutations in breast carcinoma and other cancer. Nature Genet. 13: 241-244.

Thakur, S., H.B. Zhang, Y. Peng, H. Le, B. Carroll, T. Ward, J. Yao, L.M. Farid, F.J. Couch, R.B. Wilson, and B.L. Weber. 1997. Localization of BRCAl and a splice variant identifies the nuclear localization signal. Mol. Cell. Biol. 17: 444-452.

Thompson, M.E., R.A. Jensen, P.S. Obermiller, D.L. Page, and J.T. Holt. 1995. Decreased expression of BRCA1 accelerates growth and is often present during sporadic breast cancer progression. Nature Genet. 9: 444-450.

Thorlacius, S., G. Olafsdottir, L. Tryggvadottir, S. Neuhausen, J.G. Jonasson, S. Tavtigian, H Tulinius, H.M. Ögmunsdottir, and J.E. Eyfjörd. 1996. A single BRCA2 mutation in male and female breast cancer families from Iceland with varied cancer phenotypes. Nature Genet. 13: 117-119.

Vaughn, J.P., P.L. Davis, M.D. Jarboe, G. Huper, A.C. Evans, R.W. Wiseman, A. Berchuck, J.D. Iglehart, P.A. Futreal, and J.R. Marks. 1996a. BRCA1 expression is induced before DNA synthesis in both normal and tumor-derived breast cells. Cell Growth Differ. 7: 711-715.

Vaughn, J.P., F.D. Cirisano, G. Huper, A. Berchuck, P.A. Futreal, J.R. Marks, and J.D. Iglehart. 1996b. Cell cycle control of BRCA2. Cancer Res. 56: 4590-4594.

Wilkinson, D.G. 1992. Whole-mount in situ hybridization of vertebrate embryos. In In situ hybridization: A practical approach (ed. D.G. Wilkinson), pp. 75-83. IRL Press, Oxford, UK.

Wilkinson, D.G., S. Bhatt, and B.G. Herrmann. 1990. Expression pattern of the mouse $\mathrm{T}$ gene and its role in mesoderm formation. Nature 343: 657-659.

Wilson, C.A., M.N. Payton, G.S. Elliot, F.W. Buaas, E.E. Cajulis, D. Grosshans, L. Ramos, D.M. Reese, D.J. Slamon, and F.J. Calzone. 1997. Differential subcellular localization, expression and biological toxicity of BRCA1 and the splice variant BRCA1- $\Delta 11$ b. Oncogene 14: 1-16.

Wooster, R., G. Bignell, J. Lancaster, S. Swift, S. Seal, J. Mangion, N. Collins, S. Gregory, C. Gumbs, G. Micklem, et al. 1995. Identification of the breast cancer susceptibility gene BRCA2. Nature 378: 789-792.

Wu, L.C., Z.W. Wang, J.T. Tsan, M.A. Spillman, A. Phung, X.L.
Xu, M.-C.W. Yang, L.-Y. Hwang, A.M. Bowcock, and R. Baer. 1996. Identification of a RING protein that can interact in vivo with the BRCA1 gene product. Nature Genet. 14: 430440.

Xu, C.-F., M.A. Brown, J.A. Chambers, B. Griffiths, H. Nicolai, and E. Solomon. 1995. Distinct transcription start sites generate two forms of BRCA1 mRNA. Hum. Mol. Genet. 4: 2259-2264.

$\mathrm{Xu}, \mathrm{C}$.-F. and E. Solomon. 1996. Mutations of the BRCA1 gene in human cancer. Cancer Biol. 7: 33-40.

Yeom, Y., G. Fuhrmann, C.E. Ovitt, A. Brehm, K. Ohbo, M. Gross, K. Hübner, and H.R. Schöler. 1996. Germline regulatory element of Oct-4 specific for the totipotent cycle of embryonal cells. Development 122: 881-894.

Zeitlin, S., J.-P. Liu, D.L. Chapman, V.E. Papaioannou, and A. Efstratiadis. 1995. Increased apoptosis and early embryonic lethality in mice nullizygous for the Huntington's disease gene homolog. Nature Genet. 11: 155-163. 


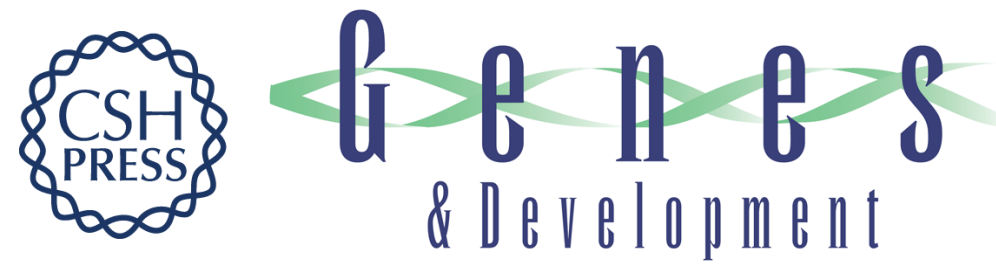

\section{Targeted mutations of breast cancer susceptibility gene homologs in mice: lethal phenotypes of Brca1, Brca2, Brca1/Brca2, Brca1/p53, and Brca2/p53 nullizygous embryos.}

T Ludwig, D L Chapman, V E Papaioannou, et al.

Genes Dev. 1997, 11:

Access the most recent version at doi:10.1101/gad.11.10.1226

References This article cites 101 articles, 23 of which can be accessed free at:

http://genesdev.cshlp.org/content/11/10/1226.full.html\#ref-list-1

License

Email Alerting Receive free email alerts when new articles cite this article - sign up in the box at the top Service right corner of the article or click here.

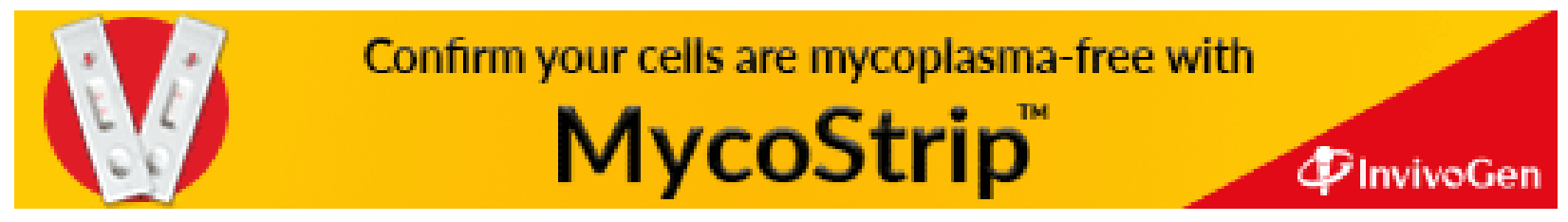

